\title{
Innovation Enablers for Innovation Teams - A Review
}

\author{
Mikael Johnsson \\ Blekinge Institute of Technology, Department of Mechanical Engineering, Blekinge Tekniska \\ Högskola, 37179 Karlskrona, Sweden \\ mikael.johnsson@bth. se
}

\begin{abstract}
This review consolidates research on innovation enablers for innovation teams, defined within this research as factors that enable a crossfunctional team within an organization to conduct innovation work, to provide a deeper understanding of what factors enable innovation teams to conduct innovation work, which means that this research involves three areas to provide a holistic picture: the organizational context, the team itself, and the individuals within the innovation team. A systematic database search was conducted in which 208 relevant articles were identified and analyzed thematically way. Twenty innovation enablers related to innovation teams were identified: awareness, capabilities, climate, collaboration, culture, dedication, economy, education, empowerment, entre- / intrapreneurship, human resources, incentives, knowledge, knowledge management, management, mind-set, need, processes, strategy, and time. This review contributes to prior research a deeper understanding of what key factors enable innovative work for innovation teams. Suggestions of both academic and practical use for the identified innovation enablers are included in this review, and direction for future research is suggested.
\end{abstract}

Keywords. Innovation, Innovation Management, Innovation Enabler, NPD.

\section{$1 \quad$ Introduction}

Innovation is needed for companies who want to stay a long time in business (Dobni, 2006; Pattersson, 2009), where established companies most often have the economic resources required to conduct innovation work (López-Fernández et al., 2011). Most often, however, they need to reframe their organizations to support innovation (Tidd and Bessant, 2013), and innovation teams constitute one way of creating small units within the company or organization to conduct innovation work (Johnsson, 2014; Yu, 2010; West et al., 2004). They are useful for at least two reasons: first, teams are known to be effective, creative and agile, for example (Backström and Olson, 2010; Dew and Hearn, 2009; Wheelan 2013; Zuidema and Kleiner, 1994); second, multifunctional and cross-functional teams perform better than individuals (Arranz and Arroyabe, 2012). Their superior performance stems from the broad range of knowledge within a multifunctional team, which stimulates the creation of new ideas, increases the spread of knowledge and favors creative performance (Ahmed, 1998b; Backström and Olson, 2010; Kelly, 2005; Smart et al., 2007). 


\subsection{Aim, focus and expected use of knowledge from this research}

This research aims to conduct a literature review to identify key factors that enable an innovation team to conduct innovation work within an organization, that is, innovation enablers for innovation teams. An innovation team is affected by the organizational context (Guzzo and Dickson, 1996; Hackman, 1990), and as the team consists of individuals, there are factors affecting both the team and its members (Backström and Olson, 2010; Wheelan, 2013). Therefore, three kinds of consideration are relevant for innovation teams: the organizational context, including management, the team itself, and the individuals within the team.

By conducting a review of innovation enablers, with a specific focus on innovation teams, this study contributes to prior research by building on already existing knowledge in the same area and providing a holistic understanding of the factors enabling innovation teams to conduct innovation, work from organizational, team and individual perspectives. Practitioners and industry can benefit from this research when creating new innovation teams or when guiding and coaching already existing ones.

\subsection{Definitions of terms used within this review}

An innovation enabler is defined within this review to be comprised of factors facilitating an innovation team in conducting innovation work within an organization. This definition builds on the definitions of "innovation," "innovation work" and "innovation teams."

An innovation is said to be an "implementation of a new or significantly improved product (or service), or process, a new marketing method, or a new organizational method in business practices, workplace organization or external relations" (OECD, 2005. p. 46). West et al. (2004) claim an innovation to be defined by the application of ideas in practice, by which someone must benefit. Andersson (1996), Lans (1997) and VINNOVA (the Swedish governmental agency for innovation systems) offer a similar definition, but add that value has to be created. I build on these prior definitions and define innovation within this review as something new that is developed and successfully implemented on the market (entailing value creation), whether an external or internal market. To make an innovation happen this requires all efforts necessary to implement the developed idea in the market (Andersson, 1996; Baxter, 2002; Johnsson, 2009; Michanek and Breiler, 2004; Ottosson, 2012; Tidd and Bessant, 2013), efforts that are in this context defined as innovation work.

An innovation team is within this review defined by a combination of the definitions of innovation and team. A group and a team are not the same. A group is defined as a complex social system of two or more people embedded in an organization (Hoegl, 2005) striving towards common goals and a structure to fulfill the goal (Wheelan, 2013). The members in a group may not yet have "found each other" (Backström and Olson, 2010) or developed efficient ways of working together (Wheelan, 2013), and they may not perceive themselves or other members as being part of a team, according to Hoegl (2005). A team is a social system of people embedded in an organization, whose members perceive themselves as such and are perceived as members by others (Hoegl, 2005; Wheelan 2013). To become a team, a group has to 
emerge through a number of stages throughout which one of the main tasks is to have a common goal to reach (Tuckmann and Jensen, 1977; Wheelan, 2013), but as the emergence process and related team status are not focused upon in this review, the term "team" is used regardless of it current status. Therefore, the definition of an innovation team is a team with the purpose of conducting innovation work within an organization. However, within the research conducted, the term "group" was included in the literature review to ensure no relevant articles were excluded.

\section{Why enablers and not barriers?}

Is an innovation enabler the opposite of an innovation barrier? Research shows that, for example, some barriers to innovation constitute financial constraints and limited budget, resistance to change, no time for innovation work (Hassainen and Dale, 2012; Orcutt and AlKadri, 2009;) or bureaucracy (Adams et al., 2006; Amabile 1998; Backström and Olson, 2010; López-Fernández et al., 2011). On the other hand, in the way that innovation is defined one can understand it as a complex situation to handle, and one could expect problems (barriers) to appear along the way. Problems can in some cases even be seen as a positive to innovation work, as they require creative solutions that might lead to completely new solutions (Johnsson, 2009). Two methods to apply to innovation work are suggested by Ottosson (2012): the first is to deliberately aim to solve $80 \%$ of a work task and leave the remaining $20 \%$ to be solved later on. This method means that problems of different kinds can be left to be solved at better times or when new knowledge concerning the work task is generated; the second methodology is to compare innovation work to running water. As running water passes rocks or other obstacles "without problem," one can use the same metaphor when conducting innovation work. Chose another path if obstacles bar the current path. The bottom line is this: Do not let problems, barriers, hindrances, roadblocks, or holdups of any other description stop the team from reaching the goal. Instead, "just take another path." My conclusion is that barriers to innovation are just a part of the innovation team's process to handle, finding solutions whenever they appear. For that reason, this review focuses only on innovation enablers.

\subsection{Previous knowledge on innovation enablers}

A literature review with focus to reveal reviews on innovation enablers was conducted to gain knowledge on the research field. Twelve reviews were detected, demonstrating a scattered area of 41 explicit factors considered to enable innovation work. From an organizational perspective seven enablers were identified, i.e. collaboration (Aagard \& Gertsen, 2011; López-Fernández and Serrano-Bedina, 2011; Ross et al., 2012; West et al., 2004; Yu, 2010, culture (Aagard \& Gertsen, 2011; Balsamo et. al., 2008; Denti and Hemlin, 2012; Smith et al., 2008; Yu, 2010, education (Aagard \& Gertsen, 2011; West et al., 2004; Yu, 2010), knowledge (Aagard \& Gertsen, 2011; López-Fernández and Serrano-Bedina, 2011; Ross et al., 2012), management (Aagard \& Gertsen, 2011; Denti and Hemlin, 2012; Gambatese and Hallowell (2011); López-Fernández and Serrano-Bedina, 2011; Smith et al., 2008), strategy Aagard \& Gertsen, 2011, Manley, 2006; Smith et al., 2008) and structure (Denti and Hemlin, 2012; Gambatese and Hallowell (2011); López-Fernández and Serrano-Bedina, 2011; Smith et al., 2008; Yu, 2010). 
From of a team-perspective there were four enablers identified, i.e. climate (Balsamo et. al., 2008; Denti and Hemlin, 2012; Kianto, 2011), collaboration Gambatese and Hallowell, 2011; Kianto, 2011), diversity Kianto, 2011; West et al., 2004), management (Denning, 2011; West et al., 2004)

From the individual perspective there were all unique innovation enablers, where the areas concern how the individual perceive demands (West et al.2004), is taking personal initiative (Denti and Hemlin, 2012), is self-disciplined (West et al., 2004) or is self-efficient (Denti and Hemlin, 2012).

The identified reviews were all conducted in a time span of a few years (2008-2012), except for one paper that was conducted a few years earlier (2004), providing short descriptions to each enabler. This motivates another, more in deep literature study, to reveal explicit and hidden factors enabling innovation team's innovation work where the focus is on the innovation teams' point of view alone.

\subsection{Research Question}

The main research question explored within this literature review is the following:

What factors are considered to enable an innovation team to conduct innovation work, and how can they be categorized?

\section{Methodology}

\subsection{Research design}

The research design of this review is based on a three-stage procedure: The first stage is the planning, which is to say the development of a plan for conducting the review, along with determining the aim of review, the protocol and criteria for the search for, selection of and analysis of the results. The second encompasses the execution, comprising activities such as developing keywords, conducting a review and analyzing the results. The third stage is the reporting, which involves suggestion of the academic and practical use of the results of the review (Tranfield et al., 2003).

\subsection{Planning the review}

This review was planned by defining its aim and the terms "innovation," "innovation team," and "innovation enabler," along with the choice of "enabler or barrier" to review. This definitional work was followed by developing a protocol describing how to relate to the results from the databases. The aim of the review was to identify both explicit and implicit innovation enablers for innovation teams. The selection of articles from databases was not based only on identifying specified keywords alone, but also on interpretations of titles and abstracts, in accordance with Schon's (1991) and Boyatzis's (1998) methods, to identify innovation enablers.

\subsection{Executing the review}

The keywords were developed from the starting point of "innovation enablers." Synonyms for "enablers" were identified using Microsoft Word's (version 2011, 14.4.6) tool for suggesting synonyms, followed by the identification of new 
synonyms derived from these first synonyms, using the same tool. This process was iterative, whereby one synonym led to another. No consideration was made of whether the synonyms were likely to be used or not in the research. When the synonym tool could not suggest any more synonyms, the keywords were rephrased to cover a broader area (e.g. "innovation enablers" and "enablers for innovation"). In total 47 keywords to cover "innovation enablers" were identified. The search-engine Summon was used to test and clarify what keywords were to be used in the following full-scale search, which resulted in an adjusted list of 24 keywords.

Table 1. The table demonstrates the synonyms for "innovation enablers" that were used as keywords in the database search.

\begin{tabular}{|c|c|}
\hline \# & Keyword [innovation enabler] \\
\hline 1 & "innovation enablers" \\
\hline 2 & "innovation facilitators" \\
\hline 3 & "innovation drivers" \\
\hline 4 & "innovation promoters" \\
\hline 5 & "innovation supporter" \\
\hline 6 & "innovation pros" \\
\hline 7 & "innovation incentives" \\
\hline 8 & "innovation encourager" \\
\hline 9 & "encouraging innovation" \\
\hline 10 & "innovation inspiration" \\
\hline 11 & "innovation creators" \\
\hline 12 & "innovation boosts" \\
\hline 13 & "innovation spurs" \\
\hline 14 & "innovation inducements" \\
\hline 15 & "innovation impetuses" \\
\hline 16 & "innovation impulses" \\
\hline 17 & "innovation motivators" \\
\hline 18 & "innovation stimulus" \\
\hline 19 & "stimulating innovation" \\
\hline 20 & "motivating innovation" \\
\hline 21 & "boosting innovation" \\
\hline 22 & "creating innovation" \\
\hline 23 & "supporting innovation" \\
\hline 24 & "enabling innovation" \\
\hline
\end{tabular}

As the context of innovation teams include the perspective of the organization, the team and the members of the team, a list of 27 keywords based on synonyms for 
"organization," "management," "innovation team" and "individuals" was developed by using the same tool as that used to generate synonyms for "innovation enablers."

Table 2. The table demonstrates synonyms for "organization," "innovation team" and "individuals."

\begin{tabular}{|c|c|}
\hline \# & Keyword [perspective of innovation enabler] \\
\hline 1 & "review" \\
\hline 2 & "team" \\
\hline 3 & "innovation team" \\
\hline 4 & “group” \\
\hline 5 & "innovation group" \\
\hline 6 & "individual" \\
\hline 7 & "grassroot" \\
\hline 8 & "operator" \\
\hline 9 & "operator level" \\
\hline 10 & “worker" \\
\hline 11 & "worker level" \\
\hline 12 & "employee" \\
\hline 13 & "employee level" \\
\hline 14 & "blue-collar" \\
\hline 15 & "blue-collar level" \\
\hline 16 & "white-collar" \\
\hline 17 & "innovation work" \\
\hline 18 & "work" \\
\hline 19 & "innovation job" \\
\hline 20 & "job" \\
\hline 21 & "organization" \\
\hline 22 & "management" \\
\hline 23 & "management level" \\
\hline 24 & "top management" \\
\hline 25 & "upper management" \\
\hline 26 & “senior management" \\
\hline 27 & "middle management" \\
\hline
\end{tabular}

As the keywords were developed in an iterative process, an adjusted list of 10 keywords regarding the perspective emerged from the number of hits when conducting the research in the database. 
Table 3. The table demonstrates keywords that emerged from Table 2 and were used in the database search.

\begin{aligned} & \hline$\#$ Keyword [perspective of innovation enabler] \\ & \hline 1 "review" \\ & \hline 2 "team" \\ & \hline 3 "innovation team" \\ & \hline 4 "group" \\ & \hline 5 "innovation group" \\ & \hline 6 "individual" \\ & \hline 7 "innovation work" \\ & \hline 8 "work" \\ & \hline 9 "organization" \\ & \hline 10 "management" \\ & \hline\end{aligned}

\subsection{Database search}

The data base search engine Summon was used between January to March of 2014. It was limited to a search for full-text online sources that were scholarly articles or academic journal articles, written in English. The research areas of business, economics, education, engineering, science and social sciences were included in this review. The reason these research areas were used is that innovation is a multidisciplinary area of study (as clarified in the definition of innovation). Another reason is that academic and industry interest in the work of innovation teams is connected to outcomes, such as performance and learning, that are connected to certain research areas.

All keywords in Table 1, Table 2 and Table 3 were used individually and in combination in four ways, as demonstrated in Table 4.

Table 4. The table demonstrates of how the keywords were used in the search engine Summon when identifying relevant articles from innovation enablers.

\begin{tabular}{cll}
\hline Search & Search in Title & Search in Abstract \\
\hline & Keyword used in: & Keyword used in: \\
\hline$\# 1$ & Table 1 & - \\
\hline$\# 2$ & Table 1 AND Table 2 & - \\
\hline$\# 3$ & Table 2 & Table 2 \\
\hline$\# 4$ & Table 3 & Table 1 \\
\hline
\end{tabular}

When a combination of keywords did not generate any hit, the spelling was controlled 
and adjusted if needed. The keywords were used crosswise in Summon, as demonstrated in Table 4, generating 2,402 title hits.

\subsection{Analysis of results}

A two-step-process was used to reduce the identified titles to 211 relevant articles. The first step was to identify relevant articles in which a title-selection methodology was used, where three selection criteria applied: First, the explicit terms such as "innovation team" or "innovation group," or words that could be interpreted as such, had to be a part of the title, or the article had already to have conducted a review regarding innovation enablers. Second, the abstract also had to explicitly discuss innovation enablers or indicate that innovation enablers were explicitly discussed in the article. Third, it was necessary that the article offer an organization-, team- (or group-), or individual-centered perspective. This first step reduced the number of relevant articles to 377 articles.

In the second step, the abstracts were read based on the criteria that there should be indications that the author(s) had put content to the innovation enabler; in other words, the innovation had to be described in a way that it could be understood and become useful to an innovation team's innovation work (e.g. a summary bullet-point list would not be sufficient to add value to this review). This step left 211 articles, which were read and thematically analyzed (Boyatzis, 1998; Schon, 1991) to identify innovation enablers. The focus was to identify single keywords within the identified articles that could be interpreted to represent an innovation enabler that may affect an innovation team directly. In some cases the authors demonstrated one key or main innovation enabler in an explicit way, while in other cases one main innovation enabler consisted of sub-enablers. In total, 46 articles contributed with data to several innovation enablers. The identified keywords were used to cluster them into themes, and organized based on relevance to the organization, team or individual. In total, 20 innovation enablers were identified, and they are presented in the following chapter, where each and one of them contains a description of its importance to innovation and how it might be applied in operational work of relevance to an innovation team. However, a few of the enablers affect the team on both the organizational and team level and are therefore demonstrated across several categories.

\section{Results}

Based on the thematic analysis, 20 innovation enablers were identified and divided according to their relevance at the organizational, team or individual level, demonstrated in alphabetical order in this section. The identified enablers sometimes overlap, and several of them are embedded as enablers in more than one perspective, as demonstrated in Table 5.

\subsection{Organizational perspective}

Climate. A climate refers to the manner of working together that the team has evolved based on shared perceptions of policies, practices and procedures (Anderson and West, 1998). Climate is less stable than culture and can be seen as an expression 
of culture at a specific time. Companies that create a positive climate for innovation do much better at product innovation (Cooper, 2013; Kianto 2011; Nybakk et al., 2011). An organization's creativity comes from employees, whereas the climate becomes important in the sense that it can motivate employees to be creative. An innovative climate is one key component of an innovative company, and all companies, no matter the size, can benefit economically from such a climate (Nybakk et al., 2011).

Prior research agrees that there are several aspects included in an innovative climate. However, there are some differences in how they are expressed and how many aspects scholars consider important when defining an innovative climate. Ekvall (1996) suggests ten factors that demonstrate a creative climate within an organization: challenge or motivation, freedom, idea support, liveliness or dynamism, playfulness or humor, debates, trust or openness, conflicts, risk taking, and idea time. On the other hand, Watkins and Marsick (1996) demonstrate seven factors that contribute to innovation: continuous learning, dialogue and inquiry, team learning, embedded systems, empowerment, system connections, and leadership. Ismail (2005) conducted a study in which these factors were compared, and the result was that Watkins and Marsick's factors made more significant contributions in explaining innovation than Ekvall's factors did. A few years later, Crespell and Hansen (2008) developed and validated six factors associated with innovation climate: supervisor encouragement, team cohesion, challenge, autonomy, openness to innovation, and availability of resources. Balsamo et al. (2008) evaluate an organizational climate for innovation using the VIPAT tool, and they specify nine variables: challenges and involvement; freedom; trust and openness; idea time; playfulness or humor; absence of conflicts; idea support; debates; and risk taking.

Factors similar or identical to those above are have been suggested by other researchers: for example, autonomy (Bright and Godwin, 2010; Cooper 2005; Crespell and Hansen, 2008); empowerment (Harborne, 2003; Denti and Hemlin, 2012); space for innovation (Harborne, 2003; Leavy, 2005; Weiss et al., 2011); selfconfidence in sharing ideas with others (Johnstone et al., 2011); leadership supporting internal and external networking (e.g. cross-boundary, team-work or customer relationships) (Balsamo et al., 2008; Cooper, 2005; Johnstone et al., 2011, West et al., 2004); recognition for those who innovate (Gamatese and Hallowell 2011); trust in other team members (Nanda and Singh, 2009); the involvement of people in innovation projects (Cooper 2005; Harborne, 2003); acceptance of different settings for innovation projects (Harborne, 2003); and the creation of a learning and development climate in the organization (West et al., 2004). Further on, Cooper (2005) suggests leadership to be with respect to boundary management, resource setting, and support, and all favored a model for good leadership around "management as service rather than seniority," "hands-off management" on a day-today basis, being relaxed, taking time to listen and being supportive in discussions with other people.

Culture. Culture is defined as a set of shared values, norms, and knowledge within a firm (Crespell and Hansen, 2008; Hauser, 1998; Nanda and Singh, 2009), which are partly conscious and partly subconscious, but are very hard to change (Hauser, 1998). The culture influences the behavior of members within the company, as culture 
represents the deepest level of basic values, assumptions and beliefs shared by the members, and it is established by actions, especially from leaders and managers (Chen et al., 2012; Sarros et al., 2008), such as hiring individuals with a range of abilities and interests or a variety of backgrounds and personalities, and heavily involving peers in the selection process (Leavy, 2005; Stempfle 2011). A strong culture ensures that everyone in the organization is on the same track (Nanda and Singh, 2009) and plays an important role in a firm's innovativeness (Hauser, 1998), where the culture has different roles in the innovation work. For example, in the search for and choice of problems to solve, and in the generation of solutions and implementation of solutions, Hauser (1998) and Hardakker (1998) found that an innovative culture contributed to making NPD faster to market. Further, Lemon and Sahota (2004) have identified four archetypes of culture: controlled, fuzzy, inspirational and cultivated, where a successful company needs to be able to shift from a controlled environment to a cultivated environment to become truly innovative.

Economy. Economy as an innovation enabler has been discussed in prior research in different ways, where economy becomes almost equal to what an organization invests in an innovation project in terms of resources such as time and knowledge, along with financial resources and human resources (Panayides, 2006; Smith et al., 2008). These resources are important not only for functional support, but also to show that the innovation project is valuable to the organization (Nanda and Singh, 2009).

The difference between small and large companies is huge in many respects. Small companies can be more agile and entrepreneurial in their innovation work, but large companies most often have more financial resources to spend on innovation work (López-Fernández et al., 2011) like creating a customer or supplier involvement. However, there is a need of leadership who wants to invest in risky innovation projects (Cooper, 2013). Furthermore, the research suggests that in increasing the company's capability for innovation, managers should support not only the technological or non-technological side of innovation (Camisón and Villar-López, 2012), but also the development of client relationships. This support arises through top management showing commitment, encouraging the development and implementation of new ideas and processes, and rewarding creativity that can occur anywhere in the organization (Panayides, 2006).

Management. Organizations need to continuously innovate to remain competitive (Brennan and Dooley, 2005; Dobni, 2006; Dooley et al., 2000). Management innovation is necessary to fulfill this need, and its drivers are strength of competition, threat of market entry and speed of technological change (Hecker and Ganter, 2013). Techniques to speed up management innovation include consciously selling the importance of management innovation to the organization, questioning, creating a problem-solving culture, and exposing employees to many different types of environments and different countries of operation, if available. They also include building a capacity for low-risk experimentation to increase the chance of implementation without crippling the functioning of the whole organization, using external change agents to explore new ideas, and being and acting like a serial management innovator (Birkinshaw and Mol, 2006). There is also a need to overcome managers' mental models when they reject disruptive innovation. These managers' 
strategies are built on rewarding incrementalism, ignoring the positive aspects of disruptive innovations, focusing on historical perceptions of success, creating perceptions of success that involve great efforts, and beliefs in the face of disconfirming information (Lettice and Thomond, 2008). However, there is also a to adjust the organization's management in accordance with its stage in the organization's life cycle (Koberg et al., 1996). The age of management also matters, since younger managers are most often trained in new technology and have the time to wait for pay off. This fact makes young managers more willing to invest in innovations based on new technology. Older top managers are less willing to invest in innovation, as they are at the end of their career and worry more about the short-term response to a project; they also do not invest in long-term projects (i.e. innovation projects) (Ahuja et al., 2008).

Innovations, as such, need a medium- or long-term perspective to be implemented, which requires a strong commitment related to managerial stability (Longo, 2007), along with access to skilled employees and managerial staff (Clark, 2012; Parolin et al., 2013) and managers who develop conditions to start cooperation between functions and organizations to make them more competitive (Parolin et al., 2013). The ongoing commitment of top and middle management is the main key according to Longo (2007), and Taylor and Helfat (2009) argue that middle management is the link to economic, structural, social, and cognitive activities, which are the corner stones of strategic innovation. Top and middle management play different roles. While top management is expected to establish and communicate its vision and broad goals and to commit middle management, who should plan and implement the entire innovation process, to these principles. This implementation requires a broad portfolio of skills and competences (e.g. health care planning, organization, behavior awareness, as well as negotiation and persuasion capabilities), which requires the presence of a middle management team in charge of the entire issue, a team that is sufficiently solid and integrated. To change an organization takes a long time (6-10 years), and the worst hurdles are in the second phase, after the early enthusiasm has waned, and this is why commitment is the key (Longo, 2007).

A formally structured young firm is less innovative than an informal one; however, formalization in older organizations does not have negative impact on innovation (Martinsuo et al., 2006). A flat, networked structure that facilitates communication and encourages cross-functional group operations represents the most advantageous style. Still, it is important that the management demonstrate leadership and encourage personnel to operate effectively, as teams (Dooley et al., 2000) that support divergence and convergence (Adamides and Karacapilidis, 2006) but also have the opportunity to work individually in the early phases, spurring innovation (Černe et al., 2013). Structures also include the implementation of efficient innovation processes that feed the organization with ideas to be implemented to remain competitive (Brennan and Dooley, 2005). In such processes, internal and external networks, together with customers, competitors and consultants, provide important sources of new ideas which can influence the introduction of these practices (Mol and Birkinshaw, 2009; O'Brian and Smith, 1995).

Strategic management is defined as a process that links strategic planning, implementation, and measurement in a continuous cycle of learning, building 
competencies, and achieving desired change (Olsen and Haslett, 2002). To create value by optimizing innovation processes in networks has become a highly interesting topic on a managerial level, as this practice creates new products over the short term and long term, and it generates intangible values (e.g. technology leadership and a secured position on the market) (Eschenbaecher and Graser, 2011).

Transformational leadership has important effects on creativity at both individual and organizational levels, and transformational leadership influences employees' creativity through psychological empowerment (Gumusluoglu and Ilsev, 2009). Management should broaden its understanding of individuals' need for autonomy and structure for motivation and commitment (Mansfeld et al., 2010), and it should ensure co-workers that they will not be punished for failure (De Jong and Vermeulen, 2003).

Furthermore, leaders of complex organizations should help the organization develop appropriate structure, innovation, and fitness. They should also support flexible thinking, act like symbols and enable useful behaviors (Marion and Uhl-bien, 2002). When aiming for radical innovation, the management must support capabilities and skills in three different phases: discovery (i.e. to create, recognize, elaborate, and articulately identified opportunities); incubation (i.e. to develop business plans out of the identifies opportunities); and acceleration (i.e. to ramp up the untried business to a point where it can stand on its own) (O'Connor and DeMartino, 1997)

High degrees of management support in projects has positive effects on speed to market, team learning from team crises and team anxiety. Processes regarding product development and commercialization are faster, and idea generation is more efficiently executed. However, a low degree of management support in projects does not affect the project in the opposite way, but team anxiety has been found to influence the capabilities in the product-development stage regardless of low or high level of management support. This influence means that management could encourage team members to turn stressors into high performance. A low level of encouragement is beneficial for team learning, and a high level of encouragement speeds up the product-development process. Management could support and help team members to overcome problems they face by giving direct help when needed. When teams are in crisis or anxiety, they need high levels of emotional support and encouragement from management to solve problems and speed up the development process and to launch the product successfully (Akgün et al., 2007).

To lead in the direction of innovative behavior, a leader must act as a role model, stimulating the intellectual diffusion of knowledge, spreading and sharing information and knowledge. The vision should be clear and should communicate in what direction to seek for ideas, but at the same time the leader should consult, rather than order results, which is achieved by delegating tasks where co-workers can explore and develop new insights. Even though the work should involve freedom, support of and feedback on work are essential, as well as recognition of achieved results and monitoring of progress and deviations. However, innovation work is not a single person's work; it takes various kinds of resources (De Jong and Den Hartog, 2007; Gilley et al., 2008).

An effective leader of an innovative workforce needs to foster both exploration and exploitation and has to be capable of flexibly switching between the three elements of ambidextrous leadership: fostering exploration by applying open leader behaviors, 
which include encouragement to do things differently, exploration and experimentation; giving room for independent thinking and acting; and supporting attempts to challenge established approaches (Rosing et al., 2011). Furthermore, management must consider to what extent the organization is mature enough to conduct exploration work. If there is too much tension within the organization, the development phase should be performed in external test facilities, but this tactic requires experienced project managers that can handle ambidextrous management (Hollen et al., 2013). Management needs, in addition to the ambidextrous leadership, to manage the creation and facilitation of knowledge creation in innovation projects. When top management increases its formal control, it stresses explicit knowledge, which may risk missing the vital interplay between tacit and explicit knowledge needed for knowledge creation, which in turn may reduce the overall capacity for knowledge creation and, ultimately, innovation (Richtnér and Åhlström, 2010).

However, the mix of exploring and exploiting (ambidexterity) innovation is of essence, whereas a first-mover strategy can hinder strategic innovations and a follower strategy could enhance strategic innovations if the knowledge is transformed into new developed knowledge that could be used for commercial purposes (Gebauer et al., 2012). The conflict lies in aiming for being first and being best. Innovativeness usually relates with being first, but this form of innovation is properly referred to as exploratory innovation, while another kind, exploitative innovation, is closely linked to improvements aiming at being best (Kollmann and Stöckmann, 2010). However, when planning for ambidextrous innovation work, one should consider that resource orientation (i.e. distinct resources and capabilities) improves innovation performance, while market orientation tends to result in incremental improvements (Ford and Paladino, 2013). Nevertheless, if a company concentrates only on its organizational capabilities, it will not succeed in terms of stability and sustainability (Kask, 2011). In addition, strategic ambidexterity suggests that an entrepreneurial orientation is of extra importance. The reason is that risk taking, innovativeness, pro-activeness, competitive aggressiveness, and autonomy stimulate exploratory innovation, whereas only pro-activeness and competitive aggressiveness facilitate exploitative innovation (Kollmann and Stöckmann, 2010). Another dimension to strategically plan for ambidexterity is the timing of additional innovative activities. The longer it takes for a company to launch new innovative activities, the lower its innovation performance will be, which of course is beneficial for "fast companies" over "slow companies" (Kuckertz et al., 2010). For an overall perspective, organizations need strategies that embrace portfolio management and include budgets for big and risky projects; scoring models, as opposed to financial models, incorporate step-wise investment, seeking data confirmation unconnected to ordinary gates and launching risky projects through alternative processes (Cooper, 2013). 
Strategy. Previous studies have shown that firms with an innovation strategy perform better when the innovation strategy consists of four dimensions: first, leadership priority for product innovation; second, leadership priority for process innovation; third, leadership priority for business-systems innovation; and fourth, resource commitment to research and development to gain competitive advantage (Nybakk et al., 2011). These four dimensions are useful for providing new offerings or experiences that excite the customer, to stay ahead of and outperform competitors, when entering new market segments, when creating new businesses or when building a product portfolio (Bowonder et al., 2010). Strategic innovation capacity is strengthened when managers deliberately install specific learning mechanisms on absorptive capacity, whereas knowledge recognition, assimilation and exploitation are key areas (Berghman et al., 2013).

On the operational and managerial level, a suggested strategy to apply is cooperation rather than competition. However the focus of the innovation work should be on the final market (Gibbert et al., 2002; Hine and Ryan, 1999). A company could develop innovative solutions at the level of a local or global market, but the circumstances are not the same and must be treated in that way. This difference means that both primary and secondary environmental factors should be considered in strategic decisionmaking and in improvements to dynamic capabilities (Kask, 2011).

As firms move towards establishing closer relationships with their suppliers, partners, and even competitors, a new paradigm of strategy, value creation, and organizational design appears to be emerging. Competitive advantage is based on learning and absorbing new sources of knowledge, no matter where they may be created, and is a key driver that sustains competitive advantage (Lei, 2003). However, if an organization wants to achieve innovative goals, these must be communicated and understood by all employees, enabling those employees to contribute to the expected goal in their day-to-day work (Smith et al., 2008).

Time. Management must show commitment by investing time and money to encourage the development and implementation of new ideas and processes (Yesil et al., 2013) and at the same time not overload individuals with projects (Nanda and Singh, 2009). As an employee, one should know how much time and effort one can spend on a pet project, where some organizations allocate time (e.g. 15\% of the time) to be spent on generating new ideas and working on employees' favorite projects (Nanda and Singh, 2009.)

\subsection{Team perspective}

Climate. All the factors presented regarding the climate, from the organizational perspective above, are valid from the team perspective as well, as the team can be seen as a small organization in itself (Backström et al., 2011). More specific to teams, though, team potency has been found to be important to fostering an innovative climate (i.e. attitudes such as "this team believes it can become unusually good at producing high quality work" and "this team feels it can solve any problem it encounters") (Gil et al., 2005). By contrast, it is assumed that leaders generally have a significant influence on the creation of a climate in which they, for example, act as role models, support ideas and participate in work (Denti and Hemlin, 2012). 
Collaboration. Competition is replaced by cooperation when aiming to add industry value (Hine and Ryan, 1999). Both short- and long-term collaboration or cooperation can result in innovation as a result of being more open to new ways of thinking and doing (Smith et al. 2008), whereas innovation teams are affected in two ways, namely by internal and external collaboration. Importantly, though, it may take a long time to build a good relationship, but it takes very little time to destroy one (Bush and Frohman, 1991), as collaboration builds on social interaction between individuals (Adamides and Karacapilidis, 2006). Free and open communication and information flow must be in place across both the short and long term (Balsamo et al. 2008; Bossink, 2004; Bingham, 2003; Bush and Frohman, 1991; Johannessen and Olsen, 2011; Nanda and Singh, 2009; Romero and Molina, 2011). The communication serves as a tool for knowledge sharing (Yesil et al., 2013) and should be clear, including directions, status and goals (Aagaard and Gertsen, 2011), whereas vision, strategy and operations are also of importance (Denti and Hemlin, 2012; Mansikkamäki et al., 2007; Nanda and Singh, 2009).

Cross-functional work, as internal collaboration, saves not only time and money, but also increases production and process improvements, where intangible results such as improved team-work, communication and involvement within and across groups can be seen immediately (Balsamo et al., 2008). Cross-functional teams, however, depend on factors such as open and collaborative organizational culture, participatory management style, input from sales (Cooper, 2005), and employees open to discussing and implementing new ideas within their teams (Morgan et al., 2004; Smith et al., 2008). The characteristics of their work are an overlap of design and construction phases (Bossink, 2004; Gamatese and Hallowell, 2011), making team boundaries more permeable (Aagaard and Gertsen, 2011; West et al., 2004). These characteristics also constitute interaction between the involved parties, various departments, and the employees involved in the innovation process (Nanda and Singh, 2009; Panesar and Markeset, 2008; Salge et al., 2012). On the individual level, cooperation depends on four basic attributes of the potential team members: first, clearly defined and specific specializations for every one of the members; second, the team members' clear and visible beliefs and practice of interdependence, together with some uniting attributes (e.g. their shared project); third, the members' capacity to tolerate differences and to find them enriching, a critical source of interdependence; and fourth, the team members' capacity to use various methods supporting their cooperation (Matjaz et al., 2006).

External collaboration that affects innovation teams was clustered into six groups: first, users, i.e. to interact with end, lead or extreme users to gather knowledge of the users' true environment (Ross et al. 2012; Yu, 2010); second, customers, i.e. to discover customer needs and to understand customer behavior, markets, and opportunities [Bush and Frohman, 1991; Cooper, 2005; Coviello and Joseph, 2012; Kodama, 2000; Morgan et al., 2004; Panesar and Markeset, 2008; Yu, 2010] and to involve the customer in the development process [Bossink, 2004; Coviello and Joseph, 2012]). The benefits of incorporating customers' ideas offer a faster and more efficient way to innovate than using the traditional R\&D approaches (Romero and Molina, 2011), and customers, as a source of innovation, are significantly linked to higher levels of innovation-related sales (Laursen, 2011), but co-creators should be rewarded to send signals that their input is appreciated (Romero and Molina 2011). 
Cheng et al. (2012) come the conclusion that customer involvement is not as important in new service development as in new product development, perhaps because companies lack of knowledge in building prototypes. Third, suppliers keep knowledge of new technology updated (Yu, 2010), develop new innovative applications (Bossink, 2004), or improve the effectiveness and efficiency of operations, maintenance and processes (Panesar and Markeset, 2008). Collaboration with suppliers is more important to larger companies than to small and medium-sized companies, as these are not as entrepreneurial as large companies (Jenssen and Nybakk, 2009), but the collaboration requires flexibility and sharing of ideas from both parties to support innovation (Mooi and Frambach, 2012). Fourth, networking allows for collaboration and sharing of knowledge with experts (HurmelinnaLuakkanen, 2011; Mele et al., 2012). In practice, this contribution means collaboration with experts and joint business networks (Ross et al. 2012), along with participation in conferences and courses (Jenssen and Nybakk, 2009). The benefits of networks are increased information flow (Hemlin and Olsson, 2011; López-Fernández et al., 2011), productive innovative climate (Cooper, 2005) and accumulated management know-how and intangible assets, such as brand image and prestige (López-Fernández et al., 2011). Fifth, partners facilitate strategic alliances and longterm relationships that are used for sustainable innovation results (Bossink, 2004); partnership with universities, in particular, increases a company's competitive advantage (Aagaard and Gertsen, 2011; Morgan et al., 2004). Furthermore, Birkinshaw et al. (2007) suggest that it could be of value to seek new networks in distant areas and to identify potential strategic and unusual partners when aiming for discontinued innovations, but the key questions to ask regarding the plausible innovative performance is how much a company has to learn and how well it is able to learn from its partner(s) (Sampson, 2007). Diversity in technological capabilities between partners is required for innovation, but not too big a divergence, as partners may in that case have problems learning from each other (Sampson, 2007). When creating a R\&D network, Mansikkamäki et al. (2007) suggest that the involved parties have "the right attitude," respectful confrontation with other parties, excellent communication skills, and a strong will to work together; and it should be the case that top management's interaction with external R\&D is positively related to product innovation (Jenssen and Nybakk, 2009). As a complement to alliances, Noke et al. (2008) suggest dalliances with companies having slow innovation processes, with no strings attached and no commitments other than ordinary business agreements, where they can benefit from learning and increasing disruptive innovation capacities. Sixth, competitors strengthen creativity, learning and knowledge stock, and innovation capabilities (Bucic, 2012; Morgan et al., 2004). Collaboration with competitors is recommended by Ritala and Hurmelinna-laukkanen (2009) as well, but they believe that IPR issues should be considered before entering into any collaboration of this kind. On the other side, research shows that companies tend to overestimate the risk of losing intellectual property while underestimating the benefits of exchanging ideas with external partners (Stempfle, 2011). However, when starting up new joint innovation projects, one strategy may be to avoid putting too much emphasis on details in contracts, which kills innovation, rather securing the collaboration as some kind of agreement providing trust in such innovation work (Paasi et al., 2010). 
Culture. Tolerance for failure is one key feature of an innovative culture, according to Aagaard and Gertsen (2011), but Johannessen and Olsen (2011) highlight the importance of communication capabilities as one of the major factors when building a culture of innovation, where the benefit is that the temporary mind-set in innovation projects becomes stationary and well familiar. Other researchers highlight multiple factors as a complex system that together contributes to an innovative culture. Factors such as leadership, strategy, risk-taking, empowerment, autonomy, internal and external communication and collaboration, organizational structure or learning, and trust are identified as enablers of an innovative culture, and these can be seen as enablers of an innovative climate (Balsamo et al., 2008; Claver et al., 1998; Denti and Hemlin, 2012; Donate and Guadamillas, 2011; Hauser, 1998; Leavy, 2005; McGurk and Baron, 2012; Morgan et al., 2004; Smith et al., 2008; Steele and Murray; 2004).

Economy. As mentioned above, the need for economic consideration is demonstrated in multiple dimensions. A dedicated budget and time can more quickly lead to technical innovation if combined with autonomy, but there is also a need for technical problem-solving ability achieved through cognitive resources and problem-solving capacities (West et al., 2004). Financial resources are also needed up to a certain point, or creativity will be limited as a result of people being too preoccupied with seeking financial resources, but financial resources above this point can have a negative impact on creativity (Nanda and Singh, 2009). Ross et al. (2012) suggest that a one could make a small investment to create a proof of concept that might lead to larger investments from investors.

Education. Highly innovative organizations create and maintain a learning environment by keeping the knowledge and skills of the employees up to date (Tan, 2013). Organizations with high learning orientation tend to benefit from, for example, knowledge and mistakes, generating new ideas and developing innovations (Smith et al. 2008). Training or education is directly related to identifying opportunities of innovation and has become a tool for the improvement of companies' human resources (Bozeman, 2000), for how innovation processes are handled and for planning for uncertainty (Cobo, 2013). Education in innovation skills has been developed for decades, including a focus on practical skills such as problem identification, including sketching, problem solving, decision making, and production; communication skills; and team skills (Petty, 1983; Tushman and Nadler, 1986). One important lesson, according to Petty (1983), is that the best results do not arise from engineering courses, since most often a tight timetable decreases creativity, but design projects with strong industrial interactions have positive effects on creativity. The technological development with the Internet and web-based technology has offered a movement from face-to-face sessions towards online learning and blended learning, which has in turn led to rapid education but also new pedagogical skills to tackle complexity and information overload from the Internet (Anghern and Nabeth, 1997; Chou and Chou, 2011). Along with such technological development, current research points out an increased focus on soft skills, that is, nontechnical skills such as creativity and problem solving (Nanda and Singh, 2009), collaboration critical thinking, contextual learning, searching, synthesizing information, self-direction and creativity (Cobo, 2013). The current research also highlights the need to practice opportunity identification (e.g. to find ideal systems on imaginary basis, use unexpected resources, identify contractions within a system, trim 
some elements in an existing product, add another purpose to a product, etc.) (Tan, 2013). An effective learning model is to strive for shared mental models by working with reflection and experimentation (Gieskes and Van der Heijden, 2004) and to supply educational environments including course development, collaborative learning and evaluation (Chou and Chou, 2011). However, lack of time to learn (Timmermans et al., 2011), bad preparation (e.g. as a consequence of a poorly structured agenda, poor time keeping or employees' lack of interest in learning) can significantly reduce the efficiency and effectiveness of sessions (Nanda and Singh, 2009; Evans and Waite, 2010).

Empowerment. The literature supports the view that employees who are empowered and autonomous have a greater degree of control over their work. This degree of control means that employees feel comfortable in their role as innovators in their own work environment (Bright and Godwin, 2010; Brown, 2005; Cooper 2005; Crespell and Hansen 2008; Smith et al., 2008). Empowering them to be innovate is one of the most effective ways to mobilize the energies of people to be creative (Harborne 2003; Denti and Hemlin, 2012; Nanda and Singh, 2009) and have the ability to adopt opportunities faster than others (Manley, 2006). Combined with leadership support and commitment, empowerment gives people freedom to take responsibility for innovation (Nanda and Singh, 2009; Smith et al., 2008), where transformational leadership was positively related to innovative behavior and transactional leadership was negatively related to innovative behavior (Denti and Hemlin, 2012). Freedom as a core value in stimulating creativity is manifested in autonomy, empowerment and decision-making. A balance between operational and strategic autonomy leads to innovation. Employees should be given autonomy concerning the process, but not necessarily the ends. Autonomy around the process fosters creativity because it strengthens the employees' sense of ownership over a project or a situation (Nanda and Singh, 2009). However, too much autonomy leads to a lack of focus, and too little operational autonomy creates a sense of rigidness. Efforts should be made to minimize the number of major projects each person is assigned to, or they will likely get lost, as one cannot expect people to do anything but step from the top of each pile to the next. It is shown that not only is slack important for technological innovation, but it must also be provided continuously over the organization's life cycle, including future expectations (Judge et al., 1997).

Human resources. Some researchers claim that human resources are the most important resources and are key factors of innovative organizations, as human beings are involved in the whole innovation process, and when encouraging and motivating them the company may draw from their collective wealth of knowledge (Kayabasi et al., 2013; López-Fernández et al., 2011; Steele and Murray, 2004). The benefits are better performance and better understanding of the market orientation, resulting in unique offering and having indirect effects on customer value (Paladino, 2007)

Innovative organizations make strategic choices based on human resources, and the agility and ability of employees to respond to a changing marketplace lies in the intellectual capital of a company's people. When the human resources are competitive, they can stretch the boundaries of competence into unknown or new areas. To accomplish such an extension, organizations must explicitly strive towards the attraction, development and retention of creative talent, where many innovation 
champions must be identified, recruited, developed, trained, encouraged and acknowledged throughout the organization (Chadwick and Dabu, 2009), including by managerial and non-managerial personnel (Searle and Ball, 2003). Companies must ensure that this affirmation is developed across both vertical and horizontal levels within the organization and with partners (Estrada et al., 2013). Companies should also employ people who do not seem to fit and are prepared to take risks, however, with purpose of disrupting the status quo (Nanda and Singh, 2009; Steele and Murray, 2004), or at least securing access to people who have the most knowledge of the task and the technology required to ensure its effective completion, especially if being work on across different departments (Shipton et al., 2006). To some workers, self-managed teams may be seen as desirable grants of autonomy or another way for management to enforce a "speed up" scheme (Chadwick and Dabu, 2009), but it is likely that training or team motivation has to be designed in a specific way, as these teams may work more independently than the rest of firm's collaborative areas (Donate and Guadamillas, 2011).

Need. The need to innovate has been clearly articulated for centuries. Without new ideas implemented into innovations, the organization will be terminated in the long run (Dobni, 2006). With these new innovation projects, one challenge is to understand and identify unmet needs, which can be done in two ways specified by Farris and Lane (2005). First, one can identify significant macro changes in the larger environment to frame the big picture. Second, one can identify concrete opportunities through a designed macro-environmental change. As soon as an unmet need is identified, it must be addressed to become a business opportunity and to identify core benefit for the target market. From an R\&D perspective, to maximize an R\&D innovation contribution the opportunity has to match the companies wants and needs, as well as the context and customers (Bingham 2003).

Processes. The cyclic innovation model, based on collaboration and iteration, has emerged from linear processes over time. In it, there is a clear user and customer focus (Berkhout et al., 2006; Dobni, 2006). The aim of these processes are to interact with customers, co-suppliers and internal service providers, and to explore technological opportunities; to build customer knowledge, understanding the entire system including networks; and to interact and co-develop with customers and partners to comprehend, visualize, and deliver value propositions. Four specific phases in the innovation process are suggested by Bessant (2005): search, select, implement, and learn. These core activities do not take place in isolation, but are influenced by a set of contextual factors that can be classified under the headings of innovation strategy, innovative organization and innovation linkages. In highly innovative companies, ideas come from everywhere in the organization. Most of these companies possess early feasibility tests for ideas, by which they are tested. The evaluations are generally to identify innovative modifications to the existing ideas and to make sure that new ideas do not repeat mistakes made in the past. The reason is to ensure that knowledge and learning are not lost and to check the innovation's effectiveness. The potentials and disadvantages of the ideas are clearly defined. Evaluating ideas in a way that optimizes creativity is a delicate process, as it can both increase and harm creativity, self-confidence and performance (Nanda and Singh, 2009). 
In extension of the innovation processes, several methods have emerged for their execution. The innovation cube is suggested by Narasimhalu (2005) to navigate through drivers, triggers and enablers for innovation to detect new opportunities and to define what innovation to aim for depending on circumstances and environment. Smith et al. (2012) suggests 10 steps when redesigning products: choose a target product, identify needs, choose reference products, identify components, build a component factor table, determine component factor weights, extract key components, identify conflicts, apply design principles, and verify results. Open innovation is suggested in all of the cyclic processes, but open innovation processes have both advantages and risks. The benefits are that they are faster and the potential risks are, for example, lack of coordination, mistrust and collaboration problems. The challenge for the management in the open innovation process is to determine the appropriate methods and practices for the utilization of external knowledge resources (Bergman et al., 2009). Collaborative networks offer one way to practice open innovation (Eschenbächer et al., 2011).

The operational work can be divided in two phases. In the early innovation phase brings the ideas into focus, and the later phase brings the implementation into focus; this latter phase is also where the financial risks are highest (Eschenbächer et al., 2011). Another practical approach to executing innovation work is to fail fast (i.e. to make mistakes early, learn from them, and try not to avoid failure. Instead, fall forward). Seven steps are suggested: First, decide what success and failure would look like before you launch initiative; second, convert assumptions into knowledge; third, be quick about it—fail fast; fourth, limit the downside risk—fail cheaply; fifth, limit uncertainty; sixth, build a culture that celebrates intelligent failure; and seventh, codify and share what you learned (Tahirsylaj, 2012). The fast-failure methodology is well known in software development by methods such as the scrum, which is an agile work method (Adkins, 2010). Due to the level of abstractness in innovation work, the visual design to envision processes acts as a knowledge agent in terms of "knowledge integrator" and "knowledge broker" to support innovation (Bertola and Teixeira, 2003). Technology is often used in a supportive role to ease various stages and remove the fuzziness of the innovation process (Smith et al., 2008), and rapid prototyping is used to speed up the actual innovation work, as rapid prototyping is beneficial for testing and evaluating ideas in early stages (Vashishtha et al., 2011). Both creativity and innovation processes are complex and are dependent on both individual and group efforts from divergence and convergence perspectives (Haner, 2005), but the most critical part in innovation work is finance. Another crucial aspect is that partnerships can be negatively affected due to institutional and regulatory factors, namely a lack of clear laws and rules regarding intellectual property (Chu and Andreassi, 2011).

Strategy. On the operational and managerial level, one suggested strategy is to apply is cooperation rather than competition. However the focus of the innovation work should be on the target market (Gibbert et al., 2002; Hine and Ryan, 1999). A company could develop innovative solutions on a local or a global market, but the circumstances may not remain the same and must be treated with respect to their fluctuations. This consideration means that both primary and secondary environmental factors should be considered in strategic decision-making and in improvements to dynamic capabilities (Kask, 2011). 


\subsection{Individual perspective}

Awareness. A company's success relies on maintaining the awareness of what is happening outside the company if one wants to develop new products for new lines of business (Logman, 2007; West et al., 2004), where reflection is pointed out as a key factor for innovation. When it comes to detecting new opportunities, awareness of customers' perceptions of value is of importance, as it requires a focus on benefits and cost drivers, which could be used as impulses for innovation (Chari, 2011; Logman, 2007). According to West et al. (2004), it requires awareness and knowledge to identify suitable work tasks and to choose the right tool to use according to what kind of innovation opportunity one is looking for (e.g. to identify existing opportunities). Different tools, such as lateral thinking, metaphoric thinking, positive thinking, association trigger, capturing, interpreting dreams, pattern recognition or blue ocean strategies, give different results (Tan, 2013). Park (2005) comes to the conclusion that awareness of opportunities comes from an interaction between three individual components: the entrepreneur, including institutionalization alertness and knowledge development, embracing risk, driving growth and market-driven innovation culture; the knowledge and experience within the firm, which includes new markets, customer requirements and technological expertise; and technology, which includes external technology providers.

Vaghely (2008) explains that opportunity recognition is divided in two streams: cognitive psychology, where patterns detected from impressions are compared to the environment; and social constructionism or developmental psychology, where a trialand-error-mentality is used to build knowledge. Both these streams are combined as a key to innovation in hands of entrepreneurs or companies. Nicolaou et al. (2009) claim that opportunity recognition is correlated with heritability and environmental factors, and Farris and Lane (2005) claim that opportunity identification as a skill can be learned. Another practical strategy to apply is to utilize aspects of SMEs' approach to the internet, where internalization management enables small companies to respond to the changing environment in an agile way (Abouzeedan et al., 2013).

Capabilities. Capability refers, in short description, to the deployment and reconfiguration of resources to improve productivity and achieve strategic goals (e.g. strategic innovation goals) (Camisón and Villar-López, 2012; Kindström et al., 2012), which are closely related to innovation and further on to an organization's performance (Yesil et al., 2013). As well, skills that support innovation can be honed or influenced by external factors (Bharadwaj and Menon, 2000). Technical capabilities are seen to be very important to innovation (Bossink, 2004; Manley, 2006; Cetindamar et al., 2009), as they refer to the ability to perform any relevant technical function or volume activity within the firm, including the ability to develop new products and processes and to operate facilities effectively (Camisón and VillarLópez, 2012). From this perspective, Cetindamar et al. (2009) point this out as a matter of technology management, where different capabilities are required along a six-step-process, starting from strategy and ending in a developed product on the market. The task for technology management is to adjust tools and activities according to the processes and capabilities required. From a knowledge management perspective, Cepeda and Vera (2007) suggests that managers devote more attention to identifying important knowledge and knowledge gaps concerning capabilities, 
followed by filling the identified gaps with new knowledge, resulting in improved capabilities. When handling capabilities strategically, Majumdar (1999) points out the risk of downsizing companies, with an understanding the result will be lost competences and capabilities in the company, affecting innovation in a negative way.

On the other hand, Camisón and Villar-López (2012) claim that non-technical capabilities (organizational capabilities) are equally important, as they refer to capabilities to implement new methodologies and processes and to establish knowledge of best practices. As such, personality traits for innovation become important (e.g. attraction to complexity, high energy, independence of judgment, intuition, self-confidence and ability to accommodate opposites). Furthermore, intelligence, knowledge, eagerness to learn, inquisitiveness, diversity, risk-taking and a strong desire to fulfill goals are also important (Nanda and Singh, 2009).

Dedication. Companies with a motivated workforce are able to recognize and solve current problems and bring solutions to the marketplace faster than their competitors (Hauschildt and Kirchman, 2001; McGurk and Baron, 2012; Yang et al., 2011). Employees motivation is a balance of not being bored by too little space or work not challenging enough and the opposite, a feeling of not having control (Nanda and Singh, 2009). Motivation usually comes from three sources: first, extrinsic factors (i.e. motivation that comes from outside a person and includes e.g. feedback or rewards for creative ideas) (Fairbank and Williams, 2001); the most commonly used extrinsic motivator is money (Bright and Godwin, 2010. Extrinsic motivation does not necessarily make employees passionate about their work and hence may hinder creativity in the long run (Amabile et al., 1996; Amabile, 1998; Amabile and Gryskiewicz, 1989; Ahmed, 1998b), Second are intrinsic factors (i.e. motivation that comes from a deep interest and involvement in the work, where the key is that employees are motivated by their interest and satisfaction in the work itself, and not by external pressures) (Amabile and Kramer, 2012; Bright and Godwin, 2010; Kathleen, 2012; Kayabasi et al., 2013). Some degree of pressure within the work environment has a positive influence on motivation as well, that is, if it is perceived as arising from the urgent, intellectually challenging nature of the problem itself (Amabile, 1988). Third are relational factors, (i.e. motivation coming from doing work because it provides value to others). Practical ways of getting buy-in-to engage and commit employees into innovation, and thereby put free time into work activities-include embracing the uncertainty embedded in innovation work (Kathleen, 2012; Newton, 1998), providing a long-term compensation plan, job security and timely feedback on performance (Manso, 2011), and educating employees with skills they can utilize from in their free time (Evans and Waite, 2010; Newton, 1998).

Empowerment. As demonstrated above, empowerment is related to autonomous work and freedom to work independently on work tasks. This freedom requires individual self-leadership, a process by which people learn to lead themselves with different focus for different phases in the innovation process. Fostering innovative behavior, self-leadership includes the ability to renew cognitive constructions, to create mental imaginary solutions and creative self-talk to achieve desired results (Carmeli and Weisberg, 2006). 
Entre- / intrapreneurship. Entrepreneurial and intrapreneurial behaviors have positive effects on innovation within a company and contribute to maintaining a sustainable innovation system (Dalohoun et al., 2009). Significant characteristics include that these people are opportunity driven (Ardichvili et al., 2000; Dalohoun et al., 2009; Morris et al., 2006; Rigtering and Weitzel, 2013), take risks (Baucus et al., 2008; Chen, 2007; Rigtering and Weitzel, 2013), overcome obstacles (Lukes, 2012), and break rules and standard operating procedures (Baucus et al., 2008).

However, entrepreneurs and intrapreneurs do not wait for opportunities to be found; they are made or recognized (Ardichvili et al., 2000, Dalohoun et al., 2009; Rigtering and Weitzel, 2013). Even though entrepreneurs and intrapreneurs challenge management and rules, management must be aware of and support this behavior (Baucus et al., 2008; Lukes, 2012; Vale and Addison, 2002), providing freedom "within a framework" to detect opportunities and act proactively (Chen, 2007; Lumpkin and Dess, 2001). Otherwise, these people may find another job (Morris et al., 2006).

Incentives. Building an economic model of innovation that does justice to the various aspects is, quite obviously, an impossible task (Overvest and Veldman, 2008), and incentives are a highly debated area, where research shows both positive and negative effects on motivation for innovation. Incentives include both financial compensation and nonfinancial intrinsic and extrinsic incentives, but they have different effects on innovation (Chen et al., 2012), where the structure of a firm's human resource management HRM system itself functions as a nonfinancial motivation, and compensation may help to shape employee behaviors (Chadwick and Dabu, 2009).

Innovative companies rely on personalized intrinsic rewards, where less innovative companies place almost exclusive emphasis on extrinsic awards (Nanda and Singh, 2009). Intrinsic rewards are claimed to be more motivating to innovation than extrinsic rewards, referring to job security, tolerance for early failure and timely feedback on performance (De Jong and Den Hartog, 2007; Manso, 2011; Nanda and Singh, 2009; Stempfle, 2011), having control over the small part with which they are closely involved (Cooper 2005). Extrinsic incentives have negative effects on innovation as they tend to make people risk-averse and foster the expectation that they will be compensated for every action they take (Chen et al., 2012; Judge et al., 1997, Nanda and Singh, 2009). They also tend to involve overinvestment in projects (Inderst and Klein, 2007; Inderst, 2009) and manipulation of bonuses (Holthausen et al., 1994). However, extrinsic incentives can be highly motivating if they are carefully combined with strict wage rules (Haucap and Wey, 2004), support company goals, are fair and understandable, relate to performance and expected behavior, and support creativity and personal initiative (Lukes, 2012). If employees are rewarded only for success, they will go for the "low-hanging fruits" and pursue incremental innovation that is almost certain to produce results (Stempfle, 2011; Tushman and Nadler, 1986). Hence, the best effects of incentives are the ones that are connected to performance and not activity (Sheikh, 2012). Prize awards as incentives have been used to motivate individuals, groups, and communities to accomplish diverse types of goals, but established companies tend to not participate in them because of varying levels of uncertainty and because resources spent on competition do not compensate for the associated price (Kay, 2011). When rewards are based on group effort, they support 
team spirit and create a climate in which individuals and teams cooperate and help each other with new ideas (Drake et al., 2001; Lukes, 2012,) but when employees face tournament incentives, they tend to maximize their own profits, resulting in lower firm profit (Drake et al., 2001).

Short-term incentives are associated with incremental innovation, and long-term incentives are associated with radical innovation, but companies use both systems when designing compensation systems (Cabrales et al., 2008). However, long-term incentives have positive effects on innovation $(\mathrm{Fu}, 2012)$, and companies that focus on long-term incentives are more successful (Lerner and Wulf, 2007); in these cases, ownership in IP (Liu, 2013) or stock bonuses (Chen et al., 2012; Sheikh, 2012, Manso, 2011) are commonly used as incentives. Factors that stimulate innovation at some point during an organization's development actually hinder it in other ways. For example, in late-stage firms, incentives and innovation are quite highly correlated, and centralized leadership may contribute to innovativeness in a firm's early stages, but not in later stages (Koberg et al., 1996).

Knowledge. Appropriate knowledge for innovation has become more and more important (Francois et al., 2002). Intangible assets are the lifeblood of knowledgeintensive industries where the new value added is disproportionately based on specialized, non-repetitious activities recognized as central to sustaining the competitiveness of firms and innovation systems (Kramer et al., 2011), and this type of asset has become one of the most strategically resources for successful innovation as a result of increased knowledge-based competition (Bucic, 2012). Organizational knowledge emerges when sense making, knowledge creation and decision making are connected to each other, and when a deliberate and frequent flow of information is applied to glue the three areas together, the result is, for example, innovation (Choo, 2001). However, employees need to be trained and educated before they can have a positive impact on the innovation process (Smith et al., 2008), but there is also a need for competence in the hiring of qualified personnel to participate in innovative projects (Francois et al., 2002) and use knowledge in an appropriate way, as knowledge itself does not generate any value (Hung et al., 2010). One practical way of using knowledge is to focus on the different stakeholders' changing interests during an innovation project, since knowing the nature of the interests and perceptions of the involved parties at a certain critical point leads to possible ways of engaging, which in turn may help to create a satisfying outcome from the innovation process (Weisenfeld, 2003). Another way of using knowledge is to bridge the diverse knowledge of members in a multifunctional team so knowledge gaps that are too large do not open (Jablokow and Booth, 2006).

Knowledge networks require direct and intense interaction between individuals with relevant knowledge and expertise, enabled within the structure of a socially embedded network. Tacit knowledge is often referred to as the "know-how" that individuals acquire through experience or learned from behavior in a collective context and is more slowly transferred through boundaries than explicit knowledge. Despite the understanding of interactive learning as core of innovation, tacit knowledge is often so embedded within the individual that she may be unaware of its importance (Dooley et al., 2013). The input perspective is dependent on the individual and enterprise's ability to know where to acquire tacit knowledge, as well as the enterprise's ability to 
support this knowledge. A key knowledge action is therefore to obtain tacit knowledge from people who are not necessarily only employees (internal to the enterprise), but can also be sources external to the enterprise, such as clients, suppliers or competitors. The output perspective is dependent on the individual's ability to convert the conveyed tacit knowledge into his or her own tacit knowledge. The key knowledge action is therefore to transform individual tacit knowledge into new, shared tacit knowledge. This process is possible only through frequent face-to-face contact between parties, which is dependent on geographical and social closeness. There is also a need for intensive communication in both the short term and the long term (Esterhuizen et al., 2012). The key to obtaining a long-term competitive advantage is not to be found in the administration of existing knowledge, but in the ability to constantly generate new knowledge. The process of generating knowledge can be categorized into four different knowledge-creation processes, as identified by Nonaka and Takeuchi (1995): socialization, externalization, combination and internalization. The literature provides a strong basis for the argument that knowledge management, and more specifically knowledge creation processes, could be used to improve an enterprise's innovation capability maturity (Esterhuizen et al., 2012).

Knowledge management. Knowledge management (KM) is defined as the formalized approach to managing the creation, transfer, retention, and utilization of an enterprise's explicit and tacit knowledge assets (Amalia and Nugroho, 2011; Cepeda and Vera 2007; Palacios et al., 2009; Plessis, 2007), and the term refers to intellectual capital (Masoulas, 1998; Plessis, 2007) including human capital, structural capital, and relational capital (Gaimon and Bailey, 2013; Mentzas, 2004). Knowledge management also includes innovation capital, which serves the purpose of increasing process management skills, facilitating collaboration and assisting in building competencies (Plessis, 2007; Shang et al., 2009), where important action to bring into the innovation capital of KM (i.e. innovation processes) are search, capture, articulate, contextualize, apply, evaluate, support and re-innovate (Tranfield et al., 2003). Organizations with well-developed knowledge management practices and behaviors are more innovative (Kamhawi, 2012; Liao and $\mathrm{Wu}, 2010$ ), more competitive and earn more money (Loan, 2006; McGurk and Baron, 2012), and a well-developed KM strategy is considered one reason for such success (López-Nicolás and MeronoCerdán, 2011).

KM is built on two dimensions, according to Palacios et al. (2009): principles and practices. Principles, referring to a higher level of research that is more abstract or related to ideas and practices, refer to tools and techniques to be used (Rogers, 1998) for meaningful learning (e.g. customer knowledge management to collect valuable information from the customers) (Coviello and Joseph, 2012; Gibbert et al., 2002; Hidalgo and Albors, 2008; Johannessen, 2008; McGurk and Baron, 2012), to establish measurement tools for performance (Chourides et al., 2003) and to identify gaps organizations' internal and external knowledge by focusing on people, processes and technology (Maqsood and Finegan, 2009).

Both exploration and exploitation have significant effects on innovation, and leaders play an important role in establishing the organizational conditions and infrastructure that facilitates KM (Donate and Guadamillas, 2011), such as ICT (Cormican and O'Sullivan, 2000; López-Nicolás and Merono-Cerdán, 2011; Smith et al., 2008). One 
way of reducing costly slack in production and providing slack to create innovations is to combine TQM with KM (Honarpour et al., 2012). By extension, KM must also be adjusted the company's size, accepting that small companies turn to their networks outward to manage innovation challenges, and large companies find ways to make their organizations feel smaller by creating project-based units (Andriopoulos and Lewis, 2010). This description aligns with agile organizations that have the ability to constantly sense competitive opportunities and threats and respond through innovative solutions in the form of, for instance, new products and processes by having the ability to quickly arrange the required knowledge and assets to innovate and react to a changing environment (Kamhawi, 2012)

Effective KM also contributes to organizational learning, which forms a bridge between knowledge management and organizational innovation (Liao and $\mathrm{Wu}, 2010$ ). The most competitive organizations are those with the ability to learn (i.e. to incorporate learning processes and knowledge creation into everyday operations and management where much of the learning involves converting knowledge from tacit to explicit forms) (Heffner and Sharif, 2008). As knowledge has been created, it must also be shared to become useful to the organization (McAdam, 2000), and this sharing is enabled thorough strategy and leadership, corporate culture, people, and information technology (Yesil et al., 2013), along with how knowledge flows in, across and out of the organization (McGurk and Baron, 2012).

Mind-set. People deal with the uncertainty and risk on a daily basis, but understandings of whatever uncertainty or risk is dangerous or is needed to be avoided or eliminated are personal. These understandings are powerful determinants for the tolerance of risk and uncertainty, both collectively and individually, but they are constructed, which makes risk and uncertainty neither objective nor subjective. Communication based on experience is commonly used to explore what affect a certain risk or uncertainty will have in a specific situation, potentially resulting in creative solutions. Because of their subjective nature, however, perceptions of risk and uncertainty are bound to the particular experience of an individual or of a group of people (Anderson, 2011). When a person is slightly biased in a pro-innovation way, this person may have a considerable performance advantage in many circumstances, for instance, in medium to highly complex, constant environments, when long-term considerations matter, and when firms search locally. However, a pro-innovation bias that is too distinct will make the search process inefficient and result in an exploration trap (Baumann and Martignoni, 2011). One risk that employees fear is to make fools out of themselves, and this fear relates to an organization's tolerance for trying out ideas that may fail, which makes employees unwilling to try and innovate or engage in activities apart from their day-to-day work. This problem may be overcome by spelling out the risk and what consequences an initiative will have (Nanda and Singh, 2009).

Innovation is a highly sophisticated knowledge and cognitive process. One of the key insights of an "enabling approach to innovation" is that it starts with a process of deep observation, investigation and comprehension of the object of innovation and its systemic context. To succeed, though, one must be active in the process of seeking the newness (Peschl and Fundneider, 2012). 
A positive attitude influences innovation as well, since a humorous atmosphere and, active celebration of success, and verification stories of success throughout the organization motivate employees and team work (Nanda and Singh, 2009). By extension, playing at work may stretch network boundaries to both individuals and digital equipment (Brooks and Bowker, 2011).

The creation of self-efficacy may increase one's motivation, creating greater eagerness to pursue individual ideas and more effective use of cognitive resources and having a positive effect on innovative behavior and climate (Denti and Hemlin, 2012). The same is true when building up a "we-can-do-it" mind-set (Gil et al., 2005). Selfefficacy can be built through positive feedback on conducted work; even though the work itself may be average, the positive feedback results in greater creativity and problem-solving skills. As a result, personal initiative is taken in terms of individual and team engagement in work tasks beyond the work contract, but successful team work is characterized by trust, vision, the aim of excellence, participative safety, and support for innovation, which together are likely to secure high levels of innovation (Denti and Hemlin, 2012; Kianto, 2011). However, innovation is also the art of individuals who triumph over the status quo, which includes asking questions, teaching oneself new skills, taking action, adapting and collaborating, and believing in strong results (Nanda and Singh, 2009). To make this happen, the individual must have the willingness to conduct these activities (López-Fernández et al., 2011), and this willingness is fostered by organizational culture (Smith et al. 2008).

Time. Time has been discussed in two perspectives when developing innovative and competitive products. One perspective is to use time as a key component within the product itself (i.e. to save time by reducing steps in manufacturing processes or organizing sites strategically to reduce the shipping time of components or products) (Fields, 2006). The other perspective refers to actual time for innovation work. To foster a creative milieu, which is important for innovation, one must not only have information but also enough time to engage, process and reflect on that information at all stages of a project (Anderson, 2011, 2013; Smith et al., 2008). For example, available time for idea development or technical solutions is of essence for innovation work. The more time a designer spends on defining, framing and understanding the problem, the more likely it is that a creative result will be achieved (Ross et al., 2012). 
Table 5. The table demonstrates the identified innovation enablers and articles referring to them.

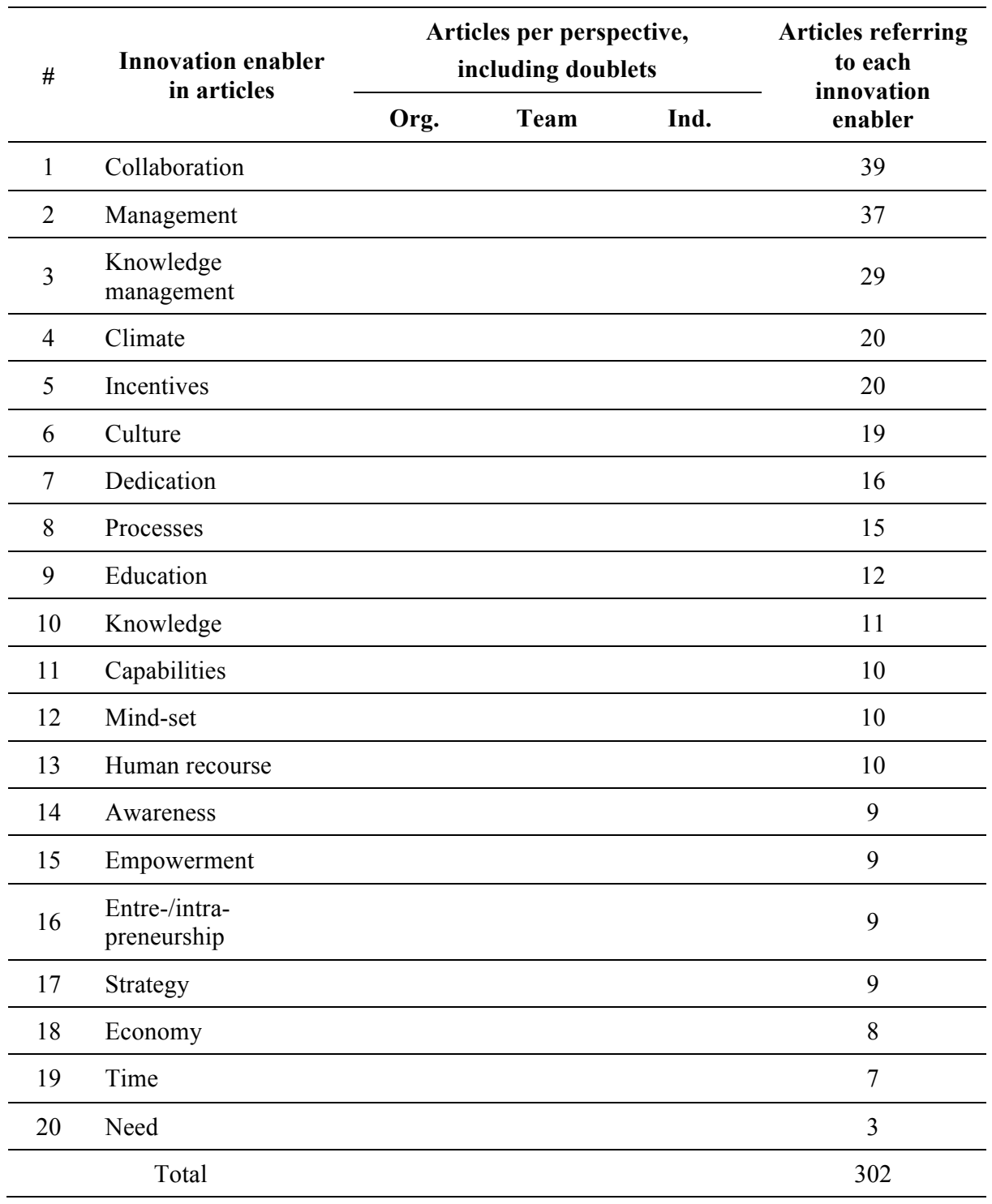




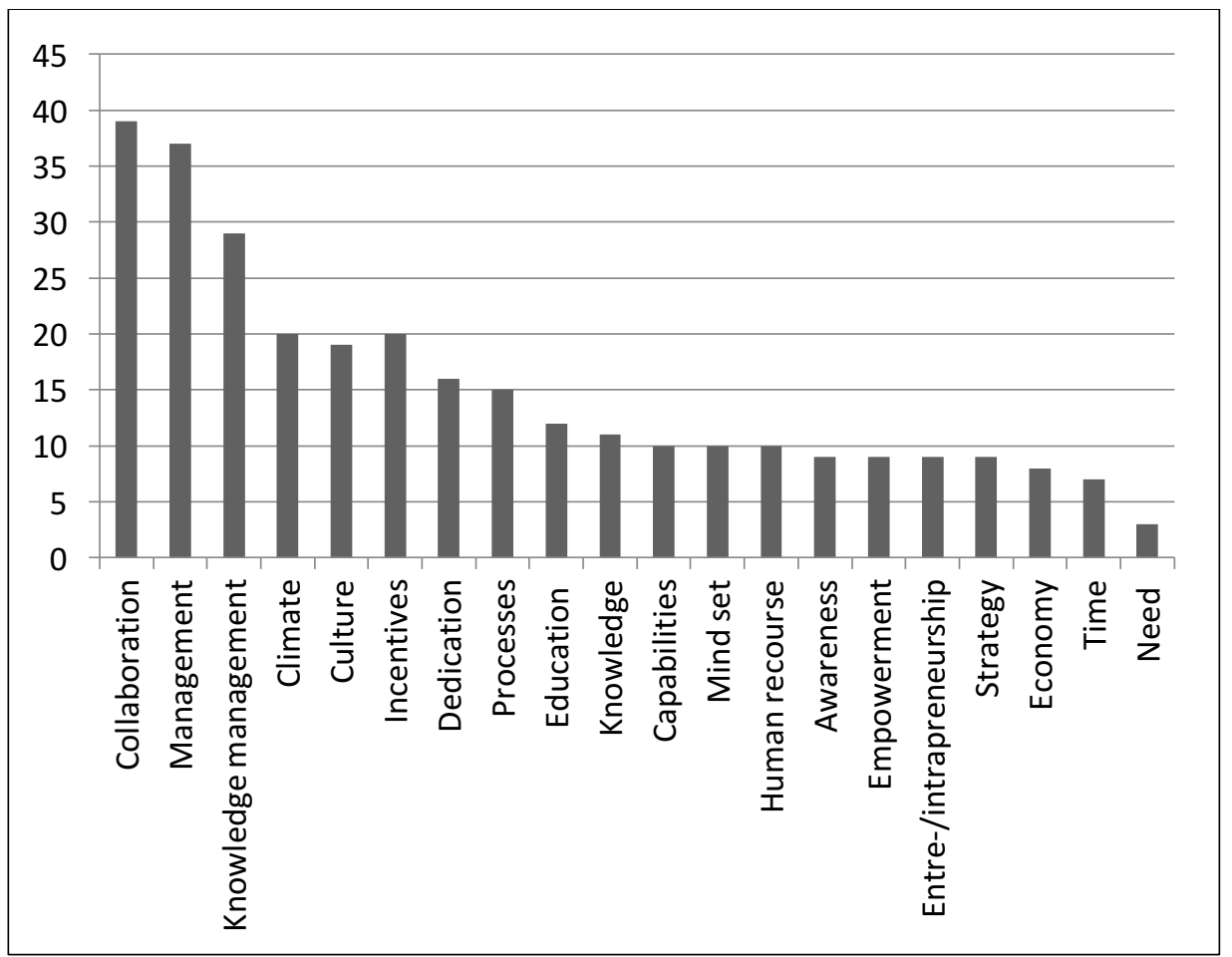

Fig. 1 - The figure demonstrates articles referring to different innovation enablers.

\section{Conclusion and future work}

The collected data were clustered into the categories of innovation enablers that enable innovation team to conduct innovation work. Out of 211 identified articles, 47 contributed with data to more than one innovation enabler, as seen in Table 5. The identified enablers were organized by levels: organizational, team, and individual. In total, 20 innovation enablers were detected. Significant results were that 39 articles referred to "collaboration" as an innovation enabler, and three articles referred to "need" as an innovation enabler. As mentioned in the research design, only articles where the author(s) provided content to the innovation enabler were collected, so if there was no explanation from which an action could be taken, the article was rejected. The findings revealed a complex picture in which descriptions of the innovation enablers overlap and intervene with each other, making them dependent on each other, to some extent. For example, management as an innovation enabler is to a certain extent one of the most powerful elements, as managers may terminate an innovation team on an official basis; on the other hand, management is not important at all, as an innovation team's dedication may have the power to move mountains and may continue working regardless of management's approval or support. Another example is "climate," concerning which the researchers include factors such as leadership, time for innovation, and so forth, and as such refer to "management." However, within this review, the thematic analysis has focused on factors that enable 
innovation teams' innovation work, by which the author could offer content to the enabler.

Additionally, this review also focuses on innovation enablers from the innovation team's point of view. Based on the results, a list of innovation enablers is suggested where the main keywords in each one of the innovation enablers are made explicit out. These innovation enablers too overlap and depend on each other, but the list provides an understanding and holistic overview of what factors enable innovation teams to conduct innovation work.

Table 7. The table demonstrates the identified innovation enablers and keywords that describe their content.

\begin{tabular}{|c|}
\hline Innovation enablers [alphabetical order] \\
\hline Awareness (E.g. ability to "see" invisible or unrevealed innovation related opportunities) \\
\hline Capabilities (E.g. skills related to management or work in an innovation project) \\
\hline Climate (E.g. OK to fail-, let's try-, let's do-mentality in work environment) \\
\hline $\begin{array}{l}\text { Collaboration (E.g. x-functional teams, collaboration between departments, suppliers and } \\
\text { customers, open innovation, networks) }\end{array}$ \\
\hline $\begin{array}{l}\text { Culture (E.g. norms and invisible rules within the organization, "this is how we do it here"- } \\
\text { mentality) }\end{array}$ \\
\hline $\begin{array}{l}\text { Dedication (E.g. factors making one feel dedicated, motivated or stimulated to work in } \\
\text { innovation projects) }\end{array}$ \\
\hline Economy (E.g. budget, non-monetary resources) \\
\hline Education (E.g. innovation-related training in theory and practice) \\
\hline $\begin{array}{l}\text { Empowerment (E.g. trust to take one's own decisions regarding resources to spend on tasks } \\
\text { to do, autonomy, interdependence) }\end{array}$ \\
\hline Entre- / intrapreneurship (E.g. doers that make things happen) \\
\hline $\begin{array}{l}\text { Human resources (E.g. access to other colleagues that could contribute to innovation project, } \\
\text { sharing competence and contributing to reduce bottle necks.) }\end{array}$ \\
\hline Incentives (E.g. monetary and non-monetary rewards) \\
\hline Knowledge (E.g. regarding innovation and expertise in an innovation project topic) \\
\hline $\begin{array}{l}\text { Knowledge management (E.g. knowledge in how to use knowledge or how to fill knowledge } \\
\text { gaps related to the innovation project) }\end{array}$ \\
\hline $\begin{array}{l}\text { Management (E.g. project managers, leadership, management support related to the } \\
\text { innovation project) }\end{array}$ \\
\hline $\begin{array}{l}\text { Mind-set (E.g. self-confidence "I can," contributing "I share," want-to develop company, } \\
\text { pro-innovation bias "I like," free-will "I want to") }\end{array}$ \\
\hline $\begin{array}{l}\text { Need (E.g. explicit and clarified need to solve for customer, organization... The "why we } \\
\text { should do this") }\end{array}$ \\
\hline
\end{tabular}

Processes (E.g. innovation process, models and best practice that guides from idea to product 
Strategy (E.g. directions in customer segment, areas, geographical markets, level of novelty on new products and technology to use or develop)

Time (E.g. time dedicated or allocated to the innovation project)

This review the area of innovation enablers from the perspective of innovation teams led the research to include also the organizational and members' perspective of an innovation team as well. This research demonstrates that innovation enablers are difficult to separate, as they interact with each other. However, 20 different innovation enablers were identified as key factors for innovation teams' innovation work, as demonstrated in Table 7.

Contribution to prior research. This research contributes to prior research by focusing on innovation enablers for innovation teams to conduct innovation work. The main contribution is to provide a holistic picture through which the scattered research field is collected, including the context of the innovation team: the organizational and team members' perspectives. Unlike many other reviews, it contributes by not only reviewing the research and identifying innovation enablers in a bullet-point list, but by also providing descriptions of what the innovation enabler is based on, making it usable for further research and practical application.

Practical applications of the results. Suggested practical use of the identified innovation enablers include, for example, the identification of innovation team's need when conducting innovation work, using the listed of innovation enablers as a checklist to fill gaps of important innovation enablers by identifying what enablers are fulfilled or not. Thus, Table 7 represents a practical template to be used as a checklist or toolkit.

Limitations within this review. As pointed out above, an innovation team admits of consideration vis a vis three different characteristics, each with a direct impact on the innovation team. However, there are other factors as well, such as policies, political directions and regional factors that affect an innovation team's innovation work directly or indirectly, but these aspects have been excluded from this review. The selected papers were identified using a specific selection methodology based on synonyms used in combination to cover a broad area of research, where papers with relevant content may not have been detected due to the author's use of other terminology than that deployed in this research, which may then affect the results.

Suggested future research. This review demonstrates innovation enablers that enable innovation teams to conduct innovation work. However, the review does not demonstrate to what degree they enable an innovation team to conduct innovation work or to what degree they are important to an innovation team. Based on this review, one cannot claim that one innovation enabler is more important than another one; rather, the review serves a greater understanding of what factors prior research suggest to be enablers of success for innovation teams. Therefore, suggestions of future research are to study the importance of innovation enablers to identify the degree to which they are important or not to innovation teams when conducting innovation work, to identify what innovation enablers are most important relative to the others, and to determine whether the importance of innovation enablers varies 
across time in an ongoing innovation project. The contribution would offer an even deeper understanding of innovation enablers in innovation work conducted by innovation teams. Further, this research could be used as a platform to build on for further reviews with the same approach, since the field is constantly growing as new papers and reviews are published.

\section{References}

Aagaard, A. \& Gertsen, F. (2011) Supporting Radical Front End Innovation: Perceived Key Factors of Pharmaceutical Innovation. Creativity and Innovation Management, 20(4), 330-346.

Abouzeedan, A. \& Klofsten, M., Hedner, T. (2013) Internetization Management as a Facilitator for Managing Innovation in High-Technology Smaller Firms. Global Business Review, (14(1), 121-136.

Adamides, E.A. \& Karacapilidis, N. (2006) Information technology support for the knowledge and social processes of innovation management. Technovation, 26, 50-59.

Adams, R, Bessant, J. \& Phelps, R. (2006), Innovation management measurement: A review. International Journal of Management Reviews, 8(21), 21-47.

Adkins, L. (2010). Coaching Agile Teams: A Companion for ScrumMasters, Agile Coaches, and Project Managers in Transition. Massachusetts, Courier.

Ahmed, P.K. (1998b). Culture and climate for innovation. European Journal of Innovation Management, 1(1), 30-43.

Ahuja, G., Lampert, C.M. \& Tandon, V. (2008) Moving Beyond Schumpeter: Management Research on the Determinants of Technological Innovation. The Academy of Management Annals, 2(1), 1-98

Akgün, A.E., Byrne, J.C., Lynn, G.S. \& Keskin, H. (2007) Team stressors, management support, and project and process outcomes in new product development projects. Technovation, 27, 628-639.

Amabile, T.M. (1988) A model of creativity and innovation in organizations. Research in organizational behavior, 10, 123-167.

Amabile, T.M. \& Gryskiewicz, N. (1989) The Creative Environment Scales: The Work Environment Inventory. Creativity Research Journal, 2, 231-254.

Amabile, T.M. \& Kramer, S. (2012) How leaders kill meaning at work. The McKinsey Quarterly, 1, 124-131.

Amabile, T.M., Conti, R., Coon, H., Lazenby, J. \& Herron, M. (1996) Assessing the work environment for creativity. Academy of Management Journal, 39, 11541184.

Amabile, T.M. (1998) How to kill creativity. Harvard Business Review, SeptemberOctober 1998, 76-87.

Amalia, M. \& Nugroho, Y. (2011) An innovation perspective of knowledge management in a multinational subsidiary. Journal of Knowledge Management. 15(1), 71-87. 
Anderson, T.D. (2011) Beyond eureka moments: supporting the invisible work of creativity and innovation. Information Research, 16(1).

Anderson, T.D. (2013) The 4Ps of innovation culture: conceptions of creatively engaging with information. Information Research, 18(3).

Anderson, N.R. \& West, M.A. (1998) Measuring climate for work group innovation: development and validation of the team climate inventory. Journal of Organizational Behavior, 19, 235-258.

Andersson, R. (1996) Uppfinnarboken - Om uppfinnandets innersta väsen (in Swedish). Malmö, Lieber-Hermods.

Andriopoulos, C. \& Lewis, M.W. (2010) Managing Innovation Paradoxes: Ambidexterity Lessons from Leading Product Design Companies. Long Range Planning, 43, 104-122.

Anghern, A. \& Nabeth, T. (1997) Leveraging Emerging Technologies in Management Education: Research and Experiences. European Management Journal, 15(3), 275-285.

Ardichvili, A., Cardozo, R. \& Ray, S. (2000) A theory of entrepreneurial opportunity identification and development. Journal of Business Venturing, 18, 105-123.

Arranz, N. \& De Arroyabe J.C.F. (2012) Can innovation network projects result in efficient performance? Technological Forecasting \& Social Change, 79, 485497.

Backström, T. \& Olson, B.K. (2010) Kaikaku - a complement to emergence based development. Paper presented at the first ICDC Conference Kobe, Japan.

Backström, T., Wilhelmson, L., Åteg, M., Olson, B.K., Moström Åberg, M. (2011), The Role of Manager in the Post-Industrial Work System. In: Studies in industrial renewal, edited by Segelod, E., Berglund. K., Bjurström, E., Dahlquist, E., Hallén, L., Johansson, L. Eskilstuna, Mdh Repro, 215-227.

Balsamo, T.J., Goodrich, N.E., Lee, J.M, Morse, T.F. \& Roberts, D.A. (2008) Identify your innovation enablers and inhibitors. Industrial Research Institute, 23-33.

Baucus, M.S., Norton Jr, W. I., Baucus, D.A. \& Human, S.E. (2008) Fostering Creativity and Innovation without Encouraging Unethical Behavior. Journal of Business Ethics, 81,97-115.

Baumann, O. \& Martignoni, D. (2011) Evaluating the New: The Contingent Value of a Pro-Innovation Bias. Schmalenbach Business Review, 63, 393-415.

Baxter, M. (2002) Product Design. Cheltenham, Nelson Thornes Ltd.

Berghman, L., Matthyssens, P., Streukens, S. \& Vandenbempt, K. (2013) Deliberate Learning Mechanisms for Stimulating Strategic Innovation Capacity. Long Range Planning, 46, 39-71.

Bergman, J., Jantunen, A. \& Saksa, J-M. (2009) Enabling Open Innovation Process Through Interactive Methods: Scenarios And Group Decision Support Systems. International Journal of Innovation Management, 13(1), 139-156.

Berkhout, A. J., Hartmann, D., Van der Duin, P. \& Ortt, R. (2006) Innovating the innovation process. Int. J. Technology Management, 34(3/4), 390-404.

Bessant, J. (2005) Enabling Continuous and Discontinuous Innovation: Learning 
From the Private Sector. Public Money \& Management, January.

Bertola, P. \& Teixeira, J.C. (2003) Design as a knowledge agent How design as a knowledge process is embedded into organizations to foster innovation. Design Studies, 24(2), 181-194.

Bharadwaj, S. A Menon, A. (2000) Making Innovation Happen in Organizations: Individual Creativity Mechanisms, Organizational Creativity Mechanisms or Both? Journal of Product Innovation Management, 17, 424-434.

Billett, S. (2001) Learning through work: workplace affordances and individual engagement. Journal of Workplace Learning, 13(5), 209-214.

Birkinshaw, J. \& Mol, M. (2006) How Management Innovation Happens. MIT Sloan Management Review, 47(4), 80-89.

Birkinshaw, J., Bessant., J. \& Delbridge, R. (2007) Finding, Forming, and Performing: Creating Networks For Discontinuous Innovation. California Management Review, 49(3), 67-84.

Bossink, B. (2004) Managing Drivers of Innovation in Construction Networks. Journal of Construction Engineering and Management, 337-345.

Bowonder, B., Dambal, A., Kumar, S. \& Shirodkar, A. (2010) Innovation Strategies for Creating Competitive Advantage. Research Technology Management, 19-32.

Boyatzis, R.E. (1998) Transforming Qualitative Information: Thematic analysis and code development. USA, SAGE Publications Inc.

Bozeman, B. (2000) Technology transfer and public policy: a review of research and theory. Research Policy, 29, 627-655.

Brennan, A. \& Dooley, L. (2005) Networked creativity: a structured management framework for simulating innovation. Technovation 25, 1388-1399.

Bright, D.S. \& Godwin, L.N. (2010) Encouraging Social Innovation in Global Organizations: Integrating Planned and Emergent Approaches. Journal of AsiaPacific Business, 11, 179-196.

Brooks, L.J., \& Bowker, G. (2011) Playing at Work: Understanding the Future of Work Practices at the Institute for the Future. Information. Communication \& Society, 5(1), 109-136.

Brown, C. (2005) Empowering innovation: extending services regionally. World Patent Information, 27, 37-41.

Bucic, t. \& Ngo, 1.v. (2012) Examining drivers of collaborative inbound open innovation: empirical evidence from Australian firms. International Journal of Innovation Management, 16(4).

Bush, J.B.Jr. \& Frohman, A.L. (1991) Communication in a "Network" Organisation.

Cabrales, À.L., Medina, C.C., Lavado, A.C. \& Cabrera, R.V. (2008) Managing functional diversity, risk taking and incentives for teams to achieve radical innovations. R\&D Management, 38(1), 35-50.

Camisón, C. \& Villar-López, A. (2012) Organizational innovation as an enabler of technological innovation capabilities and firm performance. Journal of Business Research, 67, 2891-2902. 
Carmeli, A.R.M \& Weisberg, J. (2006),"Self-leadership skills and innovative behavior at work", International Journal of Manpower, Vol. 27 Iss 1 pp. 75 90.

Cetindamar, D., Phaal, R. \& Probert, D. (2009) Understanding technology management as a dynamic capability: A framework for technology management activities. Technovation, 29, 237-246.

Cepeda, G. \& Vera, D. (2007) Dynamic capabilities and operational capabilities: A knowledge management perspective. Journal of Business Research, 60, 426437.

Černe, M., Jaklič, M. \& Škerlavaj, M. (2013) Decoupling management and technological innovations: Resolving the individualism-collectivism controversy. Journal of International Management, 19, 103-117.

Chadwick, C. \& Dabu, A. (2009) Human Resources, Human Resource Management, and the Competitive Advantage of Firms: Toward a More Comprehensive Model of Causal Linkages. Organization Science, 20(1), 253-272.

Chari, V.V., Golosov, M. \& Tsyvinski, A. (2011) Prizes and patents: Using market signals to provide incentives for innovations. Journal of Economic Theory, 147, 781-801.

Chen, M.Y-C., Lin, C.Y-Y., Lin, H-E. \& Mc.Donough, E.F. (2012) Does transformational leadership facilitate technological innovation? The moderating roles of innovative culture and incentive compensation. Asia Pac Journal Management, 29, 239-264.

Chen, M-H. (2007) Entrepreneurial Leadership and New Ventures: Creativity in Entrepreneurial Teams. Entrepreneurial Leadership and New Ventures, 16(3), 239-249.

Cheng, C.C., Chen, J-S. \& Tsou, H.T. (2012) Market-creating service innovation: verification and its associations with new service development and customer involvement. Journal of Services Marketing, 26(6), 444-457.

Choo, C.W. (2001) The knowing organization as learning organization. Education + Training, 43(4/5), 197-205.

Chou, A.Y. \& Chou, D.C. (2011) Course Management Systems and Blended Learning: An Innovative Learning Approach. Decision Sciences Journal of Innovative Education, 9(3), 463-484.

Chourides, P., Longbottom, D. \& Murphy, W. (2003) Excellence in knowledge management: an empirical study to identify critical factors and performance measures. Measuring Business Excellence, 7(2) 29-45.

Chu, D. \& Andreassi, T. (2011) Management of technological innovation. Case studies in biotechnology companies in Brazil. Management Research: The Journal of the Iberoamerican Academy of Management, 9(1), 7-31.

Clark, D. (2012) Innovation Management in SMEs: Active Innovators in New Zeeland. Journal of Small Business and Entrepreneurship, 23(4), 601-619

Claver, E., Llopis, J., Garcia, D. \& Molina, H. (1998) Organizational Culture for Innovation and New Technological Behavior. The Journal of High Technology 
Management Research, 9(1), 55-68.

Cobo, C. (2013) Mechanisms to identify and study the demand for innovation skills in world-renowned organizations. On The Horizon, 21(2), 96-106.

Cohen, W. \& Levinthal, D.A. (1990) Absorptive Capacity: A New Perspective On Learning and Innovation. Administrative Science Quarterly, 35(1), 128-152.

Cooper, P. (2005) A study of innovators' experience of new product innovation in organisations. R\&D Management, 35(5), 525-533.

Cooper, R.G. (2013) Where Are All the Breakthrough New Products? Using Portfolio Management to Boost Innovation. Research-Technology Management. 25-33

Cormican, K. \& O'Sullivan, D. (2000) A Collaborative Knowledge Management Tool for Product Innovation. In: The managing innovative manufacturing 2000 Conference, July 17th-19th, Birmingham, UK.

Coviello, N.E. \& Joseph, R.M. (2012) Creating Major Innovations with Customers: insights from Smali and Young Technology Firms. Journal of Marketing, 76, 87-104.

Crespell, P. \& Hansen, E. (2008) Managing for Innovation: Insights into a successful company. Forest Products Journal, 58(9), 6-17.

Dalohoun, D.N, Hall, A., van Mele, P. (2009) Entrepreneurship as driver of a 'selforganizing system of innovation': the case of NERICA in Benin. International Journal of Technology Management and Sustainable Development, 8(2), 87101.

De Jong, J.P.J \& Den Hartog, D.N (2007),"How leaders influence employees' innovative behaviour", European Journal of Innovation Management, Vol. 10, $41-64$.

De Jong, J.P.J. \& Vermeulen, P.A.M. (2003) Organizing successful new service development: a literature review. Management Decision, 41(9), 844-858.

Denning, S. (2011) Reinventing management: the practices that enable continuous innovation. Strategy \& Leadership, 39(3), 16-24.

Denti, L. \& Hemlin, S. (2012) Leadership and Innovation in Organizations: A Systematic Review of Factors That Mediate or Moderate the Relationship. International Journal of Innovation Management, 16(3).

Dew, R. \& Hearn, G. (2009). A new model of the learning process for innovation teams: Networked nominal pairs. International Journal of Innovation Management, 13(4), 521-535.

Dobni, C.B. (2006) The innovation blueprint. Business Horizons, 49, 329-339.

Donate, M.J. \& Guadamillas, F. (2011) Organizational factors to support knowledge management and innovation. Journal of Knowledge Management, 15(6), 890914.

Dooley, L., Cormican, K., Wreath, S. \& O'Sullivan, D. (2000) Supporting Systems Innovation. International Journal of Innovation Management, 4(3), 277-297.

Dooley, L,. Kirk, D. \& Philpott, K. (2013) Nurturing life-science knowledge discovery: managing multi-organization networks. Production Planning \& Control, 24(2-3), 195-207. 
Drake, A., Haka, S.F. \& Ravenscroft, S.P. (2001) An ABC Simulation Focusing on Incentives and Innovation. Accounting Education, 16(3), 443-471.

Du Chatenier, E., Verstegen, J.A.A.M., Biemans, H.J.A., Mulder, M. \& Omta, O. 2009 The Challenges of Collaborative Knowledge Creation in Open Innovation Teams. Human Resource Development Review, 350-381.

Du Plessis, M. (2007) The role of knowledge management in innovation. Journal of Knowledge Management, 11(4), 20-29.

Ekvall, G. (1996) Organizational climate for creativity and innovation. European Journal of Work and Organizational Psychology, 5, 105-124.

Ellström, E., Ekholm, B. \& Ellström, P.E. (2007) Two types of learning environment Enabling and constraining a study of care work. Journal of Workplace Learning, 20(2), 84-97.

Eschenbächer, J., Seifert, M. \& Thoben, K-D. (2011) Improving distributed innovation processes in virtual organisations through the evaluation of collaboration intensities. Production Planning \& Control, 22(5-6), 473-487.

Eschenbaecher, J. \& Graser, F. (2011) Managing And Optimizing Innovation Processes In Collaborative And Value Creating Networks. International Journal of Innovation and Technology Management, 8(3), 373-391.

Esterhuizen, D., Schutte, C.S.L. \& Toit, A.S.A. (2012) Knowledge creation processes as critical enablers for innovation. International Journal of Information Management, 32, 354-364.

Estrada, I., Martin-Cruz, N. \& Pérez-Santana, P. (2013) Multi-partner alliance teams for product innovation: The role of human resource management fit. Management, policy \& practice, 15(2), 161-169.

Evans, K. \& Waite, E. (2010) Stimulating the innovation potential of 'routine' workers through workplace learning. Transfer: European Review of Labour and Research, 16(2) 243-258.

Fairbank, J.F. \& Williams, S.D. (2001) Leadership And Innovation In Organizations: A Systematic Review Of Factors That Mediate Or Moderate The Relationship. Creativity and Innovation Management, 10(2), 68-74.

Farris, J. \& Lane, P. (2005) Work in Progress - Teaching Opportunity Identification. 35 th ASEE/IEEE Frontiers in Education Conference.

Fields, G. (2006) Innovation, Time, and Territory: Space and the Business Organization of Dell Computer. Economic Geography, 82(2) 119-146.

Ford, D. \& Paladino, A. (2013) Enabling Innovation through Strategic Synergies. Journal of Product Innovation Management, 30(6), 1058-1072.

Francois, J.P., Favre, F. \& Negassi, S. (2002) Competence and Organization: Two Drivers of Innovation. Economics of Innovation and New Technology, 11(3), 249-270.

$\mathrm{Fu}, \mathrm{X}$. (2012) How does openness affect the importance of incentives for innovation? Research Policy, 41, 512-523.

Gaimon, C. \& Bailey, J. (2013) Knowledge Management for the Entrepreneurial Venture. Production and Operations Management, 22(6), 1429-1438. 
Gamatese, J.A. \& Hallowell, M. (2011) Enabling and measuring innovation in the construction industry. Construction Management and Economics, 29, 553-567.

Gebauer, H., Worch, H. \& Truffer, B. (2012) Absorptive capacity, learning processes and combinative capabilities as determinants of strategic innovation. European Management Journal, 30, 57- 73.

Gibbert, M., Leibold, M. \& Probst, G. (2002) Five Styles of Customer Knowledge Management, and How Smart Companies Use Them To Create Value. European Management Journal, 20(5), 459-469.

Gieskes, J. \& Van der Heijden, B. (2004) Measuring and Enabling Learning Behaviour in Product Innovation Processes. Learning Behaviour In Product Innovation, 13(2), 109-125.

Gil, F., Rico, R., Alcover, C.M. \& Barrasa, Á. (2005) Change-oriented leadership, satisfaction and performance in work groups: Effects of team climate and group potency. Journal of Managerial Psychology, 20(3/4), 312-328.

Gilley, A., Dixon, P. \& Gilley, J.W. (2007) Characteristics of Leadership Effectiveness: Implementing Change and Driving Innovation in Organizations. Human Resource Development Quarterly, 19(2), 153-169.

Gumusluoglu, L. \& Ilsev, A. (2009) Transformational leadership, creativity, and organizational innovation. Journal of Business Research, 62, 461-473.

Guzzo, R.A. \& Dickson, M.W. (1996) Team in Organizations: Recent Research on Performance and Effectiveness. Annual Review of Psychology, 47, 307-338.

Hackman, J. R. (1990) Groups that work (and those that don't). San Francisco: Jossey-Bass.

Hallgren, E.W. (2009) How to Use an Innovation Audit as a Learning Tool: A Case Study of Enhancing High-Involvement Innovation. Creativity and Innovation Management, 18(1), 48-58.

Haner, U-E. (2005) Spaces for Creativity and Innovation in Two Established Organizations. Creativity and Innovation Management, 14(3), 288-298.

Harborne, P. \& Johne, A. (2003) Creating a Project Climate for Successful Product Innovation. European Journal of Innovation Management, 6(2), 118-132.

Hardakker, G., Ahmed, P.K. \& Graham, G. (1998) An integrated response towards the pursuit of fast time to market of NPD in European manufacturing organisations. European Business Review, 98(3), 172-177.

Hassainen, A. \& Dale, C. (2012) Drivers and barriers of new product development and innovation in event venues: A multiple case study. Journal of Facilities Management, 10(1), 75-92.

Haucap, J. \& Wey, C. (2004) Unionisation Structures And Innovation Incentives. The Economic Journal, 114, 149-165.

Hauschildt, J., Kirchmann, E. (2001) Teamwork for Innovation - The "Troika" of Promotors. R\&D Management, 31, 41-49.

Hauser, H. (1998) Organizational culture and innovativeness of firms - an integrative view. International Journal of Technology Management, 16(1/2/3), 239-256.

Hecker, A. \& Ganter, A. (2013) The Influence of Product Market Competition on 
Technological and Management Innovation: Firm-Level Evidence from a LargeScale Survey. European Management Review, 10, 17-33.

Heffner, M. \& Sharif, N. (2008) Knowledge fusion for technological innovation in organizations. Journal of Knowledge Management, 12(2), 79-93.

Hemlin, S. \& Olsson, L. (2011) Creativity-stimulating leadership: A critical incident study of leaders' influence on creativity in research groups. Creativity and Innovation Management, 20, 49-58.

Hidalgo, A. \& Albors, J. (2008) Innovation management techniques and tools: a review from theory and practice. $R \& D$ Management, (38)2, 113-127.

Hine, D. \& Ryan, N. (1999) Small service firms - creating value through innovation. Managing Service Quality, 9(6), 411-422.

Hoegl, M. (2005) Smaller teams-better teamwork: How to keep project teams small. Business Horizons, 48, 209-214.

Hollen, R.M.A., Van Den Bosch, F.A.J. \& Volberda, H.W. (2013) The Role of Management Innovation in Enabling Technological Process Innovation: An Inter-Organizational Perspective. European Management Review, 10, 35-50.

Holthausen, R.W., Larcker, D.F. \& Sloan, R.G. (1994) Annual bonus schemes and the manipulation of earnings. Journal of Accounting and Economics 19, 2974.

Honarpour, A., Jusoh, A. \& Nor, K.Md. (2012) Knowledge Management, Total Quality Management and Innovation: A New Look. Journal of Technology Management \& Innovation, 7(3), 22-31.

Hung, R.Y-Y, Lien, B.Y-H., Fang, S-C. \& McLean, G.N. (2010) Knowledge as a facilitator for enhancing innovation performance through total quality management. Total Quality Management, 21(4), 425-438.

Hurmelinna-Luakkanen, P. (2011) Enabling collaborative innovation - knowledge protection for knowledge sharing. European Journal of Innovation Management, 14(3), 303-321.

Inderst, R. \& Klein, M. (2007) Innovation, endogenous overinvestment, and incentive pay. The Rand Journal of Economics, 38(4), 881-904.

Inderst, R. (2009) Innovation management in organizations. European Economic Review, 53, 871-887.

Ismail, M. (2005) Creative climate and learning organization factors: their contribution towards innovation. Leadership \& Organization Development Journal, 26(8), 639-654.

Jenssen, J.I. \& Nybakk, E. (2009) Inter-Organizational Innovation Promoters In Small, Knowledge-Intensive Firms. International Journal of Innovation Management, 13(3), 441-466.

Jablokow, K.W. \& Booth, D.E. (2006) The impact and management of cognitive gap in high performance product development organizations. Journal of Engineering and Technology Management, 23, 313-336.

Johannessen, J-A. \& Olsen, B. (2011) Projects as communicating systems: Creating a culture of innovation and performance. International Journal of Information Management, 31, 30-37. 
Johannessen, J-A. (2008) Organisational innovation as part of knowledge management. International Journal of Information Management, 28, 403-412.

Johnsson, M. (2009) Sälj skinnet innan björnen är skjuten (in Swedish). Östertälje, Östertälje tryckeri.

Johnsson, M. (2014) Innovation Teams: Before Innovation Work is Begun. Paper presented at The $25^{\text {th }}$ ISPIM Innovation Conference in Dublin, Ireland.

Johnstone, C., Pairaudeau, G. \& Pettersson, J.A. (2011) Creativity, innovation and lean sigma: a controversial combination? Drug Discovery Today, 16(1/2), 50-57.

Judge, W.Q., Fryxell, G.E. \& Dooley, R.S. (1997) The New Task Of R\&D Management: Creating Goal-directed Communities for Innovation. California Management Review, 39(3), 72-85.

Kamhawi, E.M. (2012) Knowledge management fishbone: a standard framework of organizational enablers. Journal of Knowledge Management, 16(5), 808-828.

Kask, T. (2011) Strategic decisions as drivers of innovation: the case of MicroLink. Baltic Journal of Management, 6(3), 300-319.

Kathleen, K.M. (2012) Sustainability and Innovation. Creating Change that Engages the Workforce. JCC, 46, 175-187.

Kay, L. (2011) The effect of inducement prizes on innovation: evidence from the Ansari X Prize and the Northrop Grumman Lunar Lander Challenge. $R \& D$ Management, 41, 360-377.

Kayabasi, A. \& Duran, C., Çentindere (2013) An Analysis of the Relationship Between the Elements Encouraging Innovation and Innovation Performance for SMEs. European Journal of Business and Economics, 4.

Kelly, T. (2005) Ten faces of Innovation. USA, Broadway Business.

Kesting, P. \& Ulhöj, J.P. (2010) Employee-driven innovation: extending the license to foster innovation. Management Decision, 48(1), 65-84.

Kianto, A. (2011) Enabling Innovation in Knowledge Worker Teams. International Journal of Intellectual Capital, 8(1), 30-49.

Kindström, D. \& Kowalkowski, C., Sandberg, E. (2012) Enabling service innovation: A dynamic capabilities approach. Journal of Business Research, 66, 1063-1073.

Koberg, C.S., Uhlenbruck, N. \& Sarason, Y. (1996) Facilitators Of Organizational Innovation: The Role Of Life-Cycle Stage. Journal of Business Venturing, 11, 133-149.

Kodama, M. (2000) Creating New Services Based on the Formation of a Strategic Community with Customers: A Case Study of Innovation Involving IT and Multimedia Technology in the Field of Veterinary Medicine. Networking Veterinary Medicine Services, 9(3), 171-184.

Kollmann, T. \& Stöckmann, C. (2010) Antecedents of strategic ambidexterity: effects of entrepreneurial orientation on exploratory and exploitative innovations in adolescent organisations. International Journal of Technology Management, 52(1/2), 153-174.

Kramer, J-P., Marinelli, E., Iammarino, S. \& Diez, J.R. (2011) Intangible assets as drivers of innovation: Empirical evidence on multinational enterprises in 
German and UK regional systems of innovation. Technovation, 31, 447-458.

Kristiansen, M. \& Bloch-Poulsen, J. (2010) Employee Driven Innovation in Team. (EDIT) - Innovative Potential, Dialogue, and Dissensus. International Journal of Action Research, 6(2-3), 155-195.

Kuckertz, A. \& Kohtamäki, M., Droge gen. Körber, C. (2010) The fast eat the slow the impact of strategy and innovation timing on the success of technologyoriented ventures. International Journal of Technology Management, 52(1/2), $175-188$.

Lans, H. (1997) Uppfinn framtiden (in Swedish). Nynäshamn, Malms Repro.

Laursen, K. (2011) User-producer interaction as a driver of innovation: costs and advantages in an open innovation model. Science and Public Policy, 38(9), 713723

Leavy, B. (2005) A leader's guide to creating an innovation culture. Strategy \& Leadership, 4, 38-45.

Lei, D. (2003) Competition, cooperation and learning: the new dynamics of strategy and organization design for the innovation net. International Journal of Technology Management, 26(7), 694-716.

Lemon, M., \& Sahota, P. S. (2004) Organizational culture as a knowledge repository for increased innovative capacity. Technovation, 24(6), 483-498.

Lerner, J. \& Wulf, J. (2007) Innovation And Incentives: Evidence From Corporate R\&D. The Review of Economics and Statistics, 89(4): 634-644

Lettice, F. \& Thomond, P. (2008) Allocating resources to disruptive innovation projects: challenging mental models and overcoming management resistance. International Journal of Technology Management, 44(1/2), 140-159.

Liao,S-H. \& Wu, C-C. (2010) System perspective of knowledge management, organizational learning, and organizational innovation. Expert Systems with Applications, 37, 1096-1103.

Loan, P. (2006) Review of The New Knowledge Management: Complexity, Learning and Sustainable Innovation. On the Horizon, 14(3) 130-138.

Logman, M. (2007) Logical brand management in a dynamic context of growth and innovation. Journal of Product \& Brand Management, 16(4), 257-268.

Longo, F. (2007) Implementing managerial innovations in primary care: Can we rank change drivers in complex adaptive organizations? Health Care Management Review, 213-225.

López-Fernández, M. C., Serrano-Bedina, A. M. \& Gómez-López, R. (2011) Factors Encouraging Innovation in Spanish Hospitality Firms. Cornell Hospitality Quarterly, 52(2) 144-152.

Liu, M-S. (2013) Impact of knowledge incentive mechanisms on individual knowledge creation behavior-An empirical study for Taiwanese R\&D professionals. International Journal of Information Management, 32, 442-450.

Lukes, M. (2012) Supporting Entrepreneurial Behaviour and Innovation in Organizations. Central European Business Review Research Papers, 2, 29-36.

Lumpkin, G.T. \& Dess, G. (2001) Linking Two Dimensions Of Entrepreneurial 
Orientation To Firm Performance: The Moderating Role Of Environment And Industry Life Cycle. Journal of Business Venturing, 16, 429-451.

Majumdar, S.K. (1999) Sluggish Giants, Sticky Cultures, And Dynamic Capability Transformation. Journal of Business Venturing, 15, 59-78.

Manley, K., McFallan, S. (2006) Exploring the drivers of firm-level innovation in the construction industry. Construction Management and Economics, 24, 911-920.

Mansfeld, M.N., Hölzle, K. \& Gemünden, H.G. (2010) Personal Characteristics Of Innovators - An Empirical Study Of Roles In Innovation Managment. International Journal of Innovation Management, 14(6), 1129-1147.

Mansikkamäki, P., Mäntysalo, M. \& Rönkkä, R. (2007) Integrative Technologies Complicate Communication during Development Work Context: IndustryAcademy Collaboration. Systemics, Cybernetics And Informatics, 5(3), 9-15.

Manso, G. (2011) Motivating Innovation. The Journal of Finance, 66(5), 1823-1860.

Masoulas, V. (1998) Organizational requirements definition for intellectual capital management. International Journal of Technology Management, 16(1/2), 126144.

Maqsood, T. \& Finegan, A. (2009) A knowledge management approach to innovation and learning in the construction industry. International Journal of Managing Projects in Business, 2, 297-307.

Marion, R. \& Uhl-bien, M. (2002) Leadership in complex organizations. The Leadership Quarterly, 12, 389-418.

Martinsuo, M., Hensman, N., Artto, K., Kujala, J. \& Jaafari, A. (2006) Project-Based Management as an Organizational Innovation: Drivers, Changes, and Benefits of Adopting Project based Management. Project Management Journal, 87-97.

Matjaž, M., Kajzer, S., Potocan, V., Rosi, B. \& Knez-Riedl, J. (2006) Interdependence of systems theories - potential innovation supporting innovation. Kybernetes, 35, 942-954.

McAdam, R. (2000) Knowledge Management as a Catalyst for Innovation within Organizations: A Qualitative Study. Knowledge and Process Management, 7(4), 233-241.

McGurk, J. \& Baron, A. (2012) Knowledge management - time to focus on purpose and motivation. Strategic HR Review, 11(6), 316-321.

Mele, C., Spena, T.R. \& Colurcio, M. (2012) Co-creating value innovation through resource integration. International Journal of Quality and Service Sciences, 2(1), 60-78.

Mentzas, G. (2004) A Strategic Management Framework for Leveraging Knowledge Assests. International Journal of Innovation and Learning, 1-30.

Michanek, J. \& Breiler, A. (2004) Idéagenten - en handbok i idea management (in Swedish), Jönköping, Sweden, Brain Books AB.

Mol, M.J. \& Birkinshaw, J. (2009) The sources of management innovation: When firms introduce new management practices. Journal of Business Research, 62, 1269-1280.

Mooi, E.A. \& Frambach, R.T. (2012) Encouraging innovation in business 
relationships-A research note. Journal of Business Research, 65, 1025-1030.

Morgan, C.W., Blake, A. \& Poyago-Theotoky, J.A. (2004) The management of technological innovation: lessons from case studies in the UK food and drink industry. International Journal of Biotechnology, 5(3/4), 334-353.

Morris, M.H., Allen, J., Schindehutte, M. \& Avila, R. (2006) Balanced Management Control Systems as a Mechanism for Achieving Corporate Entrepreneurship. Journal of Managerial Issues, 18(4), 468-493.

Nanda, T. \& Singh, T.P. (2009) Determinants of creativity and innovation in the workplace: a comprehensive review. International Journal of Technology, Policy and Management, 9(1), 84-106.

Narasimhalu, A.D. (2005) Innovation Cube: Triggers, Drivers and Enablers for Successful Innovations. In: International Society of Professional Innovation Management, Porto, Portugal $19^{\text {th }}-22^{\text {nd }}$ of June.

Newton, K. (1998) The high performance workplace: HR-based management innovations in Canada. International Journal of Technology Management, 16(1/2/3), 177-192.

Nicolaou, N., Shane, S., Cherkas, L. \& Spector, T.D. (2009) Organizational Behavior and Human Decision Processes. Organizational Behavior and Human Decision Processes, 110, 108-117.

Noke, H., Perrons, R.K. \& Hughes, M. (2008) Strategic dalliances as an enabler for discontinuous innovation in slow clockspeed industries: evidence from the oil and gas industry. R\&D Management, 38, 2, 129-139.

Nonaka, I. \& Takeuchi, H. (1995) The knowledge-creating company: How Japanese companies create the dynamics of innovation. New York: Oxford University Press.

Nybakk, E., Crespell, P. \& Hansen, E. (2011) Climate for Innovation and Innovation Strategy as Drivers for Success in the Wood Industry: Moderation Effects of Firm Size, Industry Sector, and Country of Operation. Silva Fennica 45(3), 415430.

O’Brian, C. \& Smith, S.J.E. (1995) Strategies for encouraging and managing technological innovation. International Journal of Production Economics, 41, 303-310.

O'Connor, G.C. \& DeMartino, R. (1997) Organizing for Radical Innovation: An Exploratory Study of the Structural Aspects of RI Management Systems in Large Established Firms. Journal of Product Innovation Management; 23,475497.

OECD (2005) Oslo Manual - Guidelines for Collecting and Interpreting Innovation Data.

Olsen, J.E. \& Haslett, T. (2002) Strategic Management in Action. Systemic Practice and Action Research, 15(6), 449-464.

Orcutt, L.H. \& AlKadri, M.Y. (2009) Barriers and Enablers of Innovation: A Pilot Survey of Transportation Professionals. Transportation Research Record.

Ottosson, S. (2012) Dynamisk Produktutveckling (in Swedish). Floda, Tervix AB. 
Overvest, M. \& Veldman, J. (2008) Managerial Incentives for Process Innovation, Managerial and Decision. Economics, 29, 539-545.

Paasi, J., Valkokari, K., Rantala, T., Hytönen, H., Nystén-Haarala, S. \& Huhtilainen, L. (2010) Innovation Management Challenges Of A System Integrator In Innovation Networks. International Journal of Innovation Management, 14(6), 1047-1064.

Palacios, P., Gil, I. \& Garragos, F. (2009) The impact of knowledge management on innovation and entrepreneurship in the biotechnology and telecommunications industries. Small Business Economy, 32, 291-301.

Paladino, A. (2007) Investigating the Drivers of Innovation and New Product Success: A Comparison of Strategic Orientations. Journal of Product Innovation Management, 24, 534-553.

Panayides, P. (2006) Enhancing innovation capability through relationship management and implications for performance. European Journal of Innovation Management, 9(4), 466-483.

Panesar, S.S. \& Markeset, T. (2008) Development of a framework for industrial service innovation management and coordination. Journal of Quality in Maintenance Engineering, 14(2), 177-193.

Park, J.S. (2005) Opportunity recognition and product innovation in entrepreneurial hi-tech start-ups: a new perspective and supporting case study. Technovation, 25, 739-752.

Parolin, S.R.H, Vasconcellos, E., Volpato, M. \& Laurindo, A.M. (2013) Barriers and Facilitators of Collaborative Management in Technological Innovation Projects. Journal of Technology Management \& Innovation, 8, 151-164.

Pattersson, M.L. (2009). Innovation as a system. Research-technology Management, September-October: 42-51.

Peschl, M.F. \& Fundneider, T. (2012) Spaces Enabling Game-Changing and Sustaining Innovations: Why Space Matters For Knowledge Creation and Innovation. Journal of Organisational Transformation and Social Change, 9(1), 41-61.

Petty, E.R. (1983) Engineering Curricula for Encouraging Creativity and Innovation. European Journal of Engineering Education, 8, 29-43.

Richtnér, A. \& Åhlström, P. (2010) Top Management Control and Knowledge Creation in New Product Development International. Journal of Operations \& Production Management, 30(10), 1006-1031.

Rigtering, J.P.C. \& Weitzel, U. (2013) Work Context and Employee Behaviour as Antecedents for Intrapreneurship. International Entrepreneurship and Management Journal, 9, 337-360.

Ritala, P. \& Hurmelinna-Laukkanen, P. (2009) What's In It For Me? Creating And Appropriating Value In Innovation-Related Coopetition. Technovation, 29, 819828.

Rogers, E.W. (1998) Enabling Innovative Thinking: Fostering the Art of Knowledge Crafting. International Journal of Technology Management, 16(1/2/3), 11-23. 
Romero, D. \& Molina, A. (2011) Collaborative Networked Organisations and Customer Communities: Value Co-Creation and Co-Innovation in the Networking Era. Production Planning \& Control, 22(5-6), 447-472.

Rosing, K., Frese, M. \& Bausch, A. (2011) Explaining the Heterogeneity Of The Leadership-Innovation Relationship: Ambidextrous Leadership. The Leadership Quarterly, 22, 956-974.

Ross, T., Mitchell, V.A. \& May, A.J. (2012) Bottom-Up Grassroots Innovation in Transport: Motivations, Barriers and Enablers. Transportation Planning and Technology, 35(4), 469-489.

Salge, T.O., Bohné, T.M., Farchi, T. \& Piening, E.P. (2012) Harnessing The Value Of Open Innovation: The Moderating Role Of Innovation Management. International Journal of Innovation Management, 16(3).

Sampson, R.C. (2007) R\&D Alliances and Firm Performance: The Impact of Technological Diversity and Alliance Organization on Innovation. Academy of Management Journal, 50(29, 364-386.

Sarros, J. C., Cooper, B. K., \& Santora, J.C. (2008). Building a climate for innovation through transformational leadership and organizational culture. Journal of Leadership \& Organizational Studies, 15(2), 145-158.

Schon, D.A. (1991) The Reflective Practitioner - How Professionals Think in Action. Ashgate Publishing Limited, UK.

Searle, R.H. \& Ball, K.S. (2003) Supporting Innovation through HR Policy: Evidence from the UK. Creativity and Innovation Management, 12(1), 50-62.

Shang, S.S.C., Lin, S-F. \& Wu, Y-L. (2009) Service innovation through dynamic knowledge management. Industrial Management \& Data Systems, 109(3), 322337.

Sheikh, S. (2012) Do CEO compensation incentives affect firm innovation? Review of Accounting and Finance, 11(1), 4-39.

Shipton, H., West, M. A., Dawson,J., Birdi, K., \& Patterson, M. (2006). HRM as a predictor of innovation. Human Resource Management Journal, 16(1), 3-27.

Smart, P., Bessant, J. \& Gupta, A. (2007). Towards Technological Rules for Designing Innovation Networks: A Dynamic Capabilities View. International Journal of Operations \& Production Management, 27(10), 1069-1092.

Smith, M., Busi, M., Ball, P. \& Van Der Meer, R. (2008) Factors Influencing An Organisation's Ability To Manage Innovation: A Structured Literature Review And Conceptual Model. International Journal of Innovation Management, 12(4), 655-676.

Smith, S., Smith, G. \& Shen, Y-T. (2012) Redesign for Product Innovation. Design Studies, 33(2), 160-184.

Steele, J. \& Murray, M. (2004) Creating, supporting and sustaining a culture of innovation. Engineering, Construction and Architectural Management, 11(5), 316-322.

Stempfle, J. (2011) Overcoming Organizational Fixation: Creating and Sustaining an Innovation Culture. Journal of Creative Behavior, 45(2), 116-129. 
Tahirsylaj, A.S. (2012) Stimulating creativity and innovation through Intelligent Fast Failure. Thinking Skills and Creativity, 7, 265-270.

Tan, R. (2013) Seven Stimuli to Identify Opportunities of Innovation: A Practice of Training Innovative Engineers and Some Findings in China. American Journal of Industrial and Business Management, 3, 725-739.

Taylor, A. \& Helfat, C.E. (2009) Organizational Linkages for Surviving Technological Change: Complementary Assets, Middle Management, and Ambidexterity. Organization Science, 20(4), 718-739.

Tidd, J. \& Bessant, J. (2013) Managing Innovation - Integrating Technological, Market and Organizational Change, fifth edition. West Sussex, John Wiley \& Sons Ltd.

Timmermans, O., Van Linge, R., Van Petegem, P., Van Rompaey, B. \& Denekens, J. (2011) Team learning and innovation in nursing, a review of the literature. Nurse Education Today, 32, 65-70.

Tranfield; D., Young, M., Parington, D., Bessant, J. \& Sapsed, J. (2003) Knowledge Management Routines For Innovation Projects: Developing A Hierarchical Process Model. International Journal of Innovation Management, 7(1), 27-49.

Trott. P. (2012) Innovation Management and New Product Development, Fifth edition. Essex, Pearson Education Ltd.

Tuckmann, B.W. \& Jensen, M.A.C. (1977) Stages of Small-Group Development Revisited. Group and Organization Management, 2, 419-427.

Tushman, M., \& Nadler, D. (1986). Organizing for innovation. California Management Review, 28(3), 74-92.

Vaghely, I.P. \& Julien, P-A. (2008) Are opportunities recognized or constructed? An information perspective on entrepreneurial opportunity identification. Journal of Business Venturing, 25, 73-86.

Vale, P.A. \& Addison, M. (2002) Promoting Entrepreneurship and Innovation in a Large Company: Creating a Virtual Portfolio. Journal of Change Management, 2(4), 334-343.

Vashishtha, V.K., Makade, R. \& Mehla, N. (2011) Advancement of Rapid Prototyping in Aerospace Industry - A Review. International Journal of Engineering Science and Technology, 3(3), 2486-2493.

VINNOVA (2012) Innovationsledning och kreativitet i svenska företag (in Swedish). Edited by Richtner, A., Frishammar, J. Sweden, Edita.

Watkins, K.E. \& Marsick, V. (1996), Dimensions of the Learning Organization Questionnaire. Partners of the Learning Organization, Warwick, RI.

Weisenfeld, U. (2003) Engagement in Innovation Management: Perceptions and Interests in the GM Debate. Engagement in Innovation Management, 12(4), 211220.

Weiss, M., Hoegl, M., Gibbert, M. (2011) Making Virtue of Necessity: The Role of Team Climate for Innovation in Resource-Constrained Innovation Projects. Journal of Product Innovation Management, 28(S1), 196-207.

West, M., Hirst, G., Richter, A. \& Shipton, H. (2004) Twelve steps to heaven: 
Successfully managing change through developing innovative teams. European Journal of Work and Organizational Psychology, 13(2), 269-299.

Wheelan, S. A. (2013) Creating Effective Teams - A Guide for Members and Leaders. Lund, Studentlitteratur AB

Yang, Y. \& Konrad, A.M. (2011) Diversity and organizational innovation: The role of employee involvement Journal of Organizational Behavior, Journal of Organizational Behaviour, 32, 1062-1083.

Yesil, S., Büyükbese, T. \& Koska, A. (2013) Exploring The Link Between Knowledge Sharing Enablers, Innovation Capability And Innovation Performance. International Journal of Innovation Management, 17(4).

Yu, D., Hang, C.C. (2010) A Reflective Review of Disruptive Innovation Theory. International Journal of Management Reviews, 12, 435-452.

Zuidema, K.R., Kleiner, B.H. (1994) Self-directed work groups gain popularity. Business Credit, 96(9), 21-26. 